University of San Diego

Digital USD

1991-05-01

\title{
Baccalaureate Reentry Students: Effects of Professional Support on Role Conflict and Role Transition
}

Ruth N. Grendell DNSc, MSN, RN

University of San Diego

Follow this and additional works at: https://digital.sandiego.edu/dissertations

Part of the Nursing Commons

\section{Digital USD Citation}

Grendell, Ruth N. DNSc, MSN, RN, "Baccalaureate Reentry Students: Effects of Professional Support on Role Conflict and Role Transition" (1991). Dissertations. 231.

https://digital.sandiego.edu/dissertations/231

This Dissertation: Open Access is brought to you for free and open access by the Theses and Dissertations at Digital USD. It has been accepted for inclusion in Dissertations by an authorized administrator of Digital USD. For more information, please contact digital@sandiego.edu. 


\title{
Baccalaureate Reentry students: \\ Effects of Professional Support on Role Conflict and \\ Role Transition
}

by

Ruth N. GrendelI, MSN, RN

\author{
A dissertation presented to the \\ FACULTY OF THE PHILIP $Y$. HAHN SCHOOL OF NURSING \\ UNIVERSITY OF SAN DIEGO \\ In partial fulfillment of the \\ requirements for the degree \\ DOCTOR OF NURSING SCIENCE
}

May 1991 
Abstract

An increasing number of registered nurses and other health care providers are entering upper division academic nursing programs to obtain the baccalaureate nursing degree. A path analytic model was developed to examine the interrelationships of multiple roles and focal role commitments, previous education, work experience, and role conflicts perceived by reentry adult students, and the influence of professional support in the subsequent transition to the professional role. Group differences between Registered Nurses (RNs) and military corpsmen were also investigated for the variables of importance.

A sample of 206 RNs and 37 U. S. Navy corpsmen (from a current population of 96) enrolled in generic baccalaureate nursing programs throughout the country responded to a selfreport instrument protocol comprised of the Grendell Intrarole Conflict Inventory, the Goldberger Professional Support Scale, the Pieta Role conceptions Scale, and a demographic information sheet.

Data were analyzed by multiple regression procedures to determine validity of the model. Predictor variables of multiple roles, work role, professional support, and role conflict explained $4 \%$ of the variance in professional role transition, $4 \%$ in role conflict, and $3 \%$ in professional support. The strongest predictor for professional role conception discrepancy was role conflict. The strongest 
predictor for service role conception discrepancy was the work role. Multiple role occupancy was the strongest predictor of role conflict. Multiple role occupancy and work role had a salient effect on professional support. Due to the relatively small sample of military students, a comparison group, matched by age and gender, was selected from the larger group of RNs. Analysis of variance techniques were used for testing the hypotheses of group differences. Although the groups did not differ on professional role transition, differences were found in levels of education and current work hours, thus indicating that the RN group had more years of education and continued to work more hours while attending classes. Role conflict scores for the RN group were also higher. Results of the current study suggested a revised model for future testing. The similarities found among the two groups may provide the basis for identifying and refining study variables. 
Copyright 1991 by Ruth N. Grendell

All Rights Reserved 


\section{DEDICATION}

This dissertation is dedicated to my husband, Robert, who has lived the "Returning to School Syndrome" with me during the Baccalaureate, Master's and Doctoral studies. He has been a constant source of encouragement and support. 
I wish to thank the many people who have supported me throughout my doctoral education. I give special thanks and acknowledgement to my research committee. Their input and support have been invaluable. Dr. Mary Quayhagen, Dr. Patricia Roth, and Dr. Mary Scherr have graciously shared their time, ideas, and suggestions to facilitate the dissertation process. Dr. Quayhagen has served as mentor and principal guide. Dr. Roth has had a major role in my education at the baccalaureate, master's, and doctoral levels. Dr. Scherr has provided the expertise of the professional educator.

I also express my thanks to the nursing faculty who have contributed to my education during the last several years. I especially wish to recognize Dr. Jacqueline Fawcett, Dr. Jan Thompson, Dr. Evelyn Anderson, and Dr. Irene Palmer (Dean Emerita) who introduced me to the doctoral studies and new ways of thinking.

My appreciation is also given to my peers who have given their support. Special thanks go to my friends Diane Goldberger, Susan Harris, Marjorie Bendik, Merrilee Allen, Karen Heroman, Willa Fields, and Linda Urden.

I am grateful for the suggestions provided by $\mathrm{Dr}$. Barbara Pieta and for permission to use the Nursing Role Conception Instrument for this study. Special mention is 
also given to Dr. Patricia Anderson, Dr. Michael Beebe and Marilyn Allen who helped with setting up the computer files, and to Ann Ruppert, Sharon Bull, and Clem Guthro, resource librarians at Point Loma Nazarene College, who assisted me in computer searches and in locating references. Thanks, also, to my co-workers who provided support and understanding when work and study commitments sometimes conflicted.

Special love and appreciation go to my son, Bruce, and daughter, Claudia, (and our "new" daughter, Sandy, and son, Jay) who have helped me to see the humor in the midst of turmoil, and expressed their confidence in my ability to accomplish what sometimes seemed to be an impossible task. However, this endeavor would not have been possible without the love and support from my husband, Robert. He has lived the "Returning to School syndrome" with me. In addition to his help with typing, editing, and emotional support, he has taken on many of the household responsibilities including the major portion of our parent obligations in the preparations for the recent weddings of both of our children. For these gifts of love and many other measures of support, I thank you. 
Table of Contents

Page

Abstract

ii

Dedication. . . . . . . . . . . . . . . . . . v

Acknowledgements . . . . . . . . . . . . . . . . vi vi

List of Tables . . . . . . . . . . . . . . . xi

List of Figures . . . . . . . . . . . . . . xii

List of Appendices . . . . . . . . . . . . . . xiii

CHAPTER I Scope of Problem . . . . . . . . . . . 1

Purpose of Study . . . . . . . . . . . . 3

Theoretical Framework . . . . . . . . . 3

Basic Concepts of Role Theory . . . . . 3

Structuralism . . . . . . . . . . . 4

Symbolic Interaction . . . . . . . . 5

Socialization . . . . . . . . . . . 5

Role Conflict, Ambiguity \& Role Strain . • 7

Theory of Professional Support . . . . . 9

Transition to Professional Role . . . . . 12

Development of Causal Framework . . . . . 14

Theoretical Definitions of Variables . . . 17

Hypotheses . . . . . . . . . . . . 21

Significance to Nursing . . . . . . . . 22

$\mathrm{V}$ 
Page

CHAPTER II Literature Review . . . . . . . . . 25

Relationship of Multiple Roles, Professional

Support and Role Conflict . . . . . . . 30

Relationship of Focal Role Commitment,

Professional Support and Role Conflict . . . 37

Relationships of Previous Education, Work

Experience, Professional Support,

and Role Conflict . . . . . . . . . . 46

Relationships of Professional Support, Role

Conflict, and Role Transition . . . . . . 53

Comparison of Reentry Student Groups . . . . . 68

RN Students - Group I . . . . . . . . 68

Military Students - Group II . . . . . 70

Chapter Summary . . . . . . . . . . . 73

CHAPTER III Methodology . . . . . . . . . 76

Design . . . . . . . . . . . . . . 76

Samples and Procedures . . . . . . . . . . 77

Group I - RN . . . . . . . . . . . 77

Group II - Military . . . . . . . . . 80

Comparison Small Groups . . . . . . . 83

Instruments . . . . . . . . . . . . . 83

Demographic Data . . . . . . . . . . 85

Professional Support. . . . . . . . . 85

vi 
Role Conflict . . . . . . . . . . 87

Professional Conceptions Scale . . . . 89

Data Analysis Techniques . . . . . . . . . 91

Assumptions Underlying Statistical Procedure • • 92

Bivariate Correlations and Residual Analysis . . 93

CHAPTER IV Results . . . . . . . . . . . . . 96

Verification of Measurement Properties . . . . 96

Testing of the Model . . . . . . . . . . 99

Testing the Hypotheses . . . . . . . . . 103

Explanation of Variance. . . . . . . . . . 105

Analysis of Group Differences. . . . . . . . . 107

Additional Findings . . . . . . . . . . 113

Summary. . . . . . . . . . . . . . . . . . . . . . . .

CHAPTER V Discussion . . . . . . . . . . . . . 116

Strengths and Limitations . . . . . . . . . 122

Implications for Nursing Research . . . . . 127

Implications for Nursing Practice . . . . . 129

Implications for Nursing Education . . . . . 130

Summary . • . • . . . . • . • . • . 132

References. . . . . . . . . . . . . . . . . 133

Appendices . . . . . . . . . . . . . . . . . . . . . . . . . . .

vii 
List of Tables

TABLE

Page

1 Structural Equations . . . . . . . . . . 78

2 Demographic Data - Total . . . . . . . . . 82

3. Demographic Data - 2 Groups. . . . . . . . . 84

4. Correlation Matrix of Total Model. . . . . . . . 94

5. Initial Psychometric Properties of Instruments - . 97

6. Standardized Regression Coefficients for Model • . .101

7. Comparison of Mean Scores for Model Variables. . . 104

8. Decomposition of Variance for Outcome Variables. . .106

9. Two-way Analysis of Variance by Sample, Sex. . . . 109

10. One-way Analysis of Variance Between 2 Groups. • . .110

11. One-way Analysis of Variance Between 4 Groups. . . .112

viii 


\section{List of Figures}

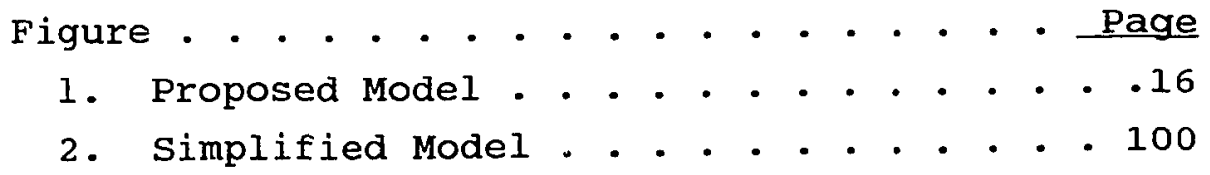




\section{List of Appendices}

Appendix

Page

A Letter to Directors of Nursing Programs . . 149

B Letter of Instructions to Consenting Faculty . 152

C Consent Form . . . . . . . . . . . . 154

D Letter to RN Participants . . . . . . . 156

E Letter from Director of Military Program . . 158

F Letter to Military Participants. . . . . . 160

G Demographic Information Sheet . . . . . . 162

H Grendell Role Conflict Inventory . . . . . . 164

I Goldberger Professional Support Scale. . . . 172

J Pieta Role Conception Scale. . . . . . . 176

$\mathrm{k}$ Committee on the protection of Human Subjects

Approval Forms . . . . . . . . . . 185 
Chapter I

Scope of the Problem

The endorsement for the baccalaureate degree as the level for entry into professional practice has prompted many practicing registered nurses (RNs) to enter colleges and universities for further education. In addition, an increasing number of allied health care workers have joined RNs in seeking the advanced degree as a means of career mobility.

These mature students have been defined as nontraditional learners due to previous education, a span of time since that education, work experiences, and their investment in several significant adult social roles. These students present many challenges to faculty who are more accustomed to dealing with generic, or traditional, students who do not bring preknowledge, nursing skills, or health care work experience into the classroom. The adult's unique needs and problems also emanate from the addition of the student role and its influence on their involvement in multiple social roles, and/or commitment to a specific role (Baj, 1985; Kessler \& Henderson, 1980; Leddy \& Pepper, 1989; Queen, 1984; Raudonis, 1987) . 
Much of the nursing literature related to the reentry adult student is concerned with the female RN who continues with family and work-related responsibilities while seeking the higher degree. However, little information can be found that addresses the needs of the other adults who pursue advanced education as a means for career advancement. Although several potential causes of role conflict for the adult student have been identified, few empirical studies have been reported on the impact of role conflict, or the strategies that have assisted in resolving these problems (Lee, 1988).

of particular interest to this study is the comparison of reentry RN students and Navy Corpsmen enrolled in generic baccalaureate nursing programs. Several of the military personnel have gained licensure as vocational nurses (LVNs) due to their previous education and many years of experience in military health care settings. Some upper-division schools are now granting advanced placement to individuals through transfer of credit and/or proficiency examinations.

However, most returning students view the testing procedures as threats to self-esteem and a devaluation of previous education and work experiences. Conversely, they feel threatened when no credit is granted for their background knowledge and experience. Cherished beliefs and self-image as a competent health care provider are 
challenged by the philosophy of the baccalaureate curriculum and new role expectations, often resulting in feelings of frustration and anger (Maurin, 1983; Nuwayhid, 1984; Rather, 1990). A review of the literature supports the need for an in-depth study that addresses these issues. Purpose of the study

The purpose of this study was to examine a theoretical model depicting the relationship between role conflict and professional role transition experienced by reentry students in generic baccalaureate nursing programs. Specifically, the purpose was to investigate the influence of demographic variables (number of current roles, focal role occupancy, previous education, and work experience) and professional support on perceived role conflict, and the subsequent internalization of professional role concepts. A second purpose of the study was to examine group differences in the variables of the model between $\mathrm{RN}$ and military reentry student groups.

\section{Theoretical Framework}

\section{Basic Concepts of Role Theory}

Role theory is used as the underlying framework for this study. Concepts from this theoretical framework have been used extensively in the social sciences, or the helping professions, primarily for the discussion and explanation of human social behavior. Role theory 
continues to gain in importance as a rationale for examining the effects of the rapid technological advances on role functions. The development of new and expanded roles has created uncertainty of expectations for many roles, and has also resulted in changes in role relationships.

Role theory, itself, embodies concepts derived from systems and social learning theories. Physiological and psychosocial aspects are incorporated into its core concepts. The metaphors and language of this framework offer a clearer perspective and increased predictive power than do other current theoretical frameworks (Hardy \& Conway, 1988). The framework chosen for the current study is based upon the three major role theory dimensions of structuralism, interactionism, and socialization (Burr, 1972; Callero, 1986; Hardy \& Conway, 1988; Rotter, 1982; Strauss, 1956).

Structuralism. An underlying assumption of the structuralist, or functionalist, perspective is that roles are socially defined and relatively stable positions that are accompanied by particular expectations. Certain roles are learned through socialization and are passed on from one generation to the next. Norms or standards are accepted facts within a social structure and serve as the framework for defining role function. Human behavior is either a direct or indirect response to role expectations 
and/or role interpretations (Callero, 1986). Thus, whether the individual is the efficient nurse, the model parent, or the ideal friend is measured by the expectations of individuals and significant others within the relationship.

Symbolic interaction. The interactionist approach interprets human behavior as a response to the symbolic acts of others. Role is defined as a set of behaviors expected of one individual toward the partner during an interaction (Nuwayhid 1984). Rather than viewing role as a relatively stable concept, role is described as ever changing in response to the individual's interpretation of the event and the feedback from individuals involved in the interaction. The role position incorporates all associated symbols and behaviors, and aids in the prediction of human behavior. Self-identity is considered to be multifaceted and a product of interrelationships in response to the complex nature of societies (stryker \& Statham, 1985) .

This perspective is frequently used in studying the dynamic process of role change and the evolvement of roles over time (Hardy \& Conway, 1988). Lynn, McCain, and Boss (1989) advocate the use of symbolic interaction as a means for conducting research with reentry students.

Socialization. Socialization, another central concept related to symbolic interaction, encompasses all 
processes that help to integrate a newcomer into a given environment or situation. Every interaction is a socializing experience, and many roles are learned through role-playing, and communication with significant others or reference groups. However, the accuracy of these actions does not guarantee smooth and cooperative social interaction due to individual interpretation of events (Stryker \& Statham, 1985).

The expectations of reference groups have a powerful influence in the socialization process. The person who aspires to membership in a group will strive to meet the expectations of that group (Lum, 1988). Such groups offer positive and negative cues that enable the person in self-appraisal and to identify with the role.

The use of these experiences, patterns, and symbols are labeled as anticipatory socialization. The individual learns the norms of the role before actually assuming the role. The amount of anticipatory socialization positively influences the ease of transition into roles. Within this perspective, socialization is viewed as the process of shaping self-images (Hardy \& Conway, 1988; Queen, 1984; Rendon, 1988; Stryker \& Statham, 1985). Imitation and reinforcement are components of learning, predictions can be made regarding the patterns of behavior, and behavior is seen as being goal-directed (Murdaugh \& Hinshaw, 1986; Rotter, 1982). 
Role conflict, role ambiguity, and role strain.

Role conflict is a condition in which the individual

is unable to meet expectations of others or self for a given role (Hardy \& Conway, 1988). Role conflict may be the result of incongruity with personal values, role overload, role incompetence, or overqualification. Role ambiguity occurs when expectations of the relationship partners are vague and not clearly defined, or when the individual is uncertain about the role expectations. The inability to resolve these problems leads to role strain which is a perceived, or subjective, difficulty in fulfilling role obligations (Goode, 1960).

The degree of role strain is closely associated with the number of roles, commitment to a significant role, and amount of activity required by the individual. Many roles are dependent upon one another requiring double obligations of the individual (Burr, 1972; Goode, 1960).

The resolution of role strain is accomplished through the use of personal resources and problem-solving techniques. Conflict resolution is a complicated process and the person may use a variety of strategies to eliminate the discomfort. Role bargaining, or negotiation, allows the individual to retain some control over situations. The outcomes of unresolved role strain are tension, frustration, and anxiety (Goode, 1960; Hardy \& Conway, 1988) . 
Although most sociologists are concerned with the role strain brought upon by multiple role conflict, Marks (1977) proposed that what may be an overwhelming situation to one person may be easily managed by another. He suggested that under normal conditions, human beings have an abundant supply of energy that can be utilized as needs arise.

His expansion theory is based upon four major concepts related to an individual's unique perception and response to role demands. These include the person's ability to conserve energy, to set priorities, and to channel energy in meeting multiple and/or specific role obligations. He suggested that energy can be found to perform a role that is highly significant to the individual with a subsequent energizing effect when the task is accomplished.

Time and energy are viewed by Marks as products or outcomes of the role bargaining rather than as limited amounts that cannot be changed. On the other hand, he stated that energy can be lacking when a particular role has little meaning to the individual. Fatigue or lack of time are frequent causes for not meeting role expectations. Enjoyment, loyalty, anticipated rewards, and avoidance of disapproval or punishment are common reasons for role commitment. 
In summary, role theory provides a useful framework for the investigation of role conflicts experienced by the reentry adult students. Multiple roles, commitment to a focal role, previous education and work experience have frequently been cited as the major contributors to role conflict for these individuals. The negative impact on learning and its influence on attrition rates have been mentioned by several authors (Baj, 1985; Beeman, 1988; Green, 1987; Hirachi \& Parlocha, 1983). Theory of Professional support

Professional or formal support is defined as direct and indirect problem-solving behaviors provided by a person who has a special educational background and who can provide counsel or assistance with specific problems. The professional support person is described as the provider of information, problem solver, decision maker, and overseer (Goldberger, 1987). These behaviors may include actual intervention, problem focused discussion, referrals, and suggestions. Active listening, encouragement, reflective understanding, and open access to counsel from the professional are components of professional communication skills. The reciprocal actions of giving and receiving between role partners provided through social support is not as evident in professional support relationships. (Goldberger, 1987; Gottlieb, $1978)$. 
Adjustment to the academic setting for the reentry student is frequently referred to as a crisis event (Dalme, 1983). Several documented methods used by educators to help in managing the conflicts include commitment to the unique learning needs of reentry students (Beeman, 1988); availability of a special advisor (Blatchley \& Stephan, 1985); faculty assistance in meeting future goals (Brainard, 1983); help from faculty in adjusting to the unfamiliar academic environment (Callin, $1983)$.

The value of the teacher during the role socialization process cannot be overemphasized (Sarbin \& Allen, 1968). Role model, mentor, sponsor, and coach are popular titles assigned to the educator. The expertise of the instructor can regulate the pace of learning new concepts and, also, aids in mastery of a role. The praise or criticism related to role performance provides incentives and feedback. The teacher often serves as a prompter and aids students to internalize the expected norms. This relationship between student and teacher also permits the learning of complimentary roles that will interact with the ascribed role, thus promoting identity with the role.

Dalme (1983) depicted faculty as the most significant factor in the professional socialization process, and in the development of a professional self-image (Hammer \& 
Tufts 1985). Respect, interest in, and acceptance of the individual student are hallmarks in fostering professional growth. Betz (1985) referred to educators as mediators and listeners to students' concerns as they encounter differences between the ideal and actual concepts of the nursing role. A mutual respect among faculty and practicing nurses that demonstrates a cohesiveness within the nursing profession is also an essential element. Weiss (1984) also emphasized the importance of the nurse educator's responsibility in fostering role transformation for students and nursing colleagues. Weiss identified five major concepts of the transformation process as: (1) defining and articulating the nursing domain (2) legitimizing the nursing profession (3) communicating in professional rather than non-professional modes (4) negotiating collaborative roles, and (5) cultivating the organizational network. Professional support may also come from other significant role partners or reference groups. Individuals who function in a professional role that is valued by the student provide encouragement and instruction, serve as role models, act as resource persons, and aid in decision-making (Dalme, 1983; Merton, 1957: Pieta, 1976). 
Transition to the Professional Role

Role transition. Burr (1972) stated the ease of making a successful role transition is dependent upon available resources and abilities to begin or finish a role. He discussed the positive effects of anticipatory socialization and clarity of role expectations upon the transition process. He also commented on the negative effects exerted by lack of clarity or understanding about the expectations of a given role upon the presence and degree of role strain.

Role activities that facilitate goal attainment and are valued by the individual have a positive influence on the ease of transition into that role. Role conflict is inevitable if a change is to take place; on the other hand, the amount of incompatibility between roles contributes to role strain.

Burr (1972) presented several propositions, stating that the greater amount of change that is required results in a greater difficulty in making a role transition. The length of time spent in a role and the values associated with that role can facilitate or inhibit role transition. However, motivation and the availability of substitute gratifications in taking on the new role serve as positive influences in easing the loss of the former role (Sarbin \& Allen, 1968). Enculturation to a role is achieved through practice and anticipatory socialization. 
Professional role. A profession is defined by sociologists as a vocation that provides a needed and distinctive service to a society. Members in the profession are equipped with a unique body of knowledge that has been based on practical experience, research, and theory. Socialization into the profession takes place in institutions of higher learning where students receive education in the arts, sciences, and humanities, thus providing a broad perspective for critical and creative thinking. A system for credentialing to certify competency and a process to ensure current expertise is in place.

The profession is also guided by a code of ethics which emphasizes the sense of mission, or humanitarian service, and is governed by peer review with sanctions against unethical practice. Some of the characteristics of the individual in the professional role include autonomy, identification with and commitment to the profession, accountability, collaboration, citizenship, ethical behaviors, creativity, risk-taking, and mastery of knowledge and skills (Leddy \& Pepper, 1989; Pieta, 1976; Urden, 1987) .

The concept that transition to the professional role occurs through the socialization, or enculturation, of the baccalaureate education is supported by several authors (Frisch, 1987; Goldstein, 1980; Gross, Takazawa \& Rose, 
1987; Murdaugh \& Hinshaw, 1986). Transition is also influenced by informal and formal contacts with members of reference groups who hold professional status (Corwin, 1968; Dalme, 1983; Hardy \& Conway, 1988; Pieta, 1976). The 1986 report of the American Association of Colleges of Nursing describes the essential skills that are required of the professional nurse. The report places a strong emphasis on the value of faculty members as socializing agents and as sources of support. Faculty were viewed as a major reference group through their modeling and teaching professional concepts, and by exhibiting commitment to values, traditions, responsibilities, and concerns of the profession. Role enactment is most effective when there is congruence between the self and the role (Corwin, 1968; Sarbin \& Allen, 1968). The person appears to be comfortable with the role and is committed to it. The transition from one role to another may occur in gradual and subtle ways, and the individual may not be aware of these changes. Yet, role transition is frequently referred to as a turning point or crisis event in an individual's life.

Development of the Causal Framework

The causal framework for this study involves seven variables concerning the effects of professional support and role conflict upon professional role transition for 
the reentry student. Involvement in multiple roles, responsibilities required by a focal role, and perceived threat to self-identity in a focal role have been identified as contributing factors to role conflict. Role conflict is viewed as a barrier to professional role transition. Professional support is presented as a method to assist the student in minimizing the impact of these role conflicts, and to move toward professional role transition.

The exogenous variables consist of the background characteristics of the reentry student: the number of current roles (X1), occupancy in a focal role (X2) the type or form of previous education (X3), and related work experience $(\mathrm{X} 4)$. The endogenous variables include: professional support (X5) role conflict (X6) and the final variable which is transition to the professional role (X7) -

This framework has been devised following an extensive review of the literature that describes the several significant role conflicts that pertain to these variables, the factors that help to alleviate these problems, and assist with the transition to the professional role. The graphic representation of the model and time sequence are pictured in Figure 1. 


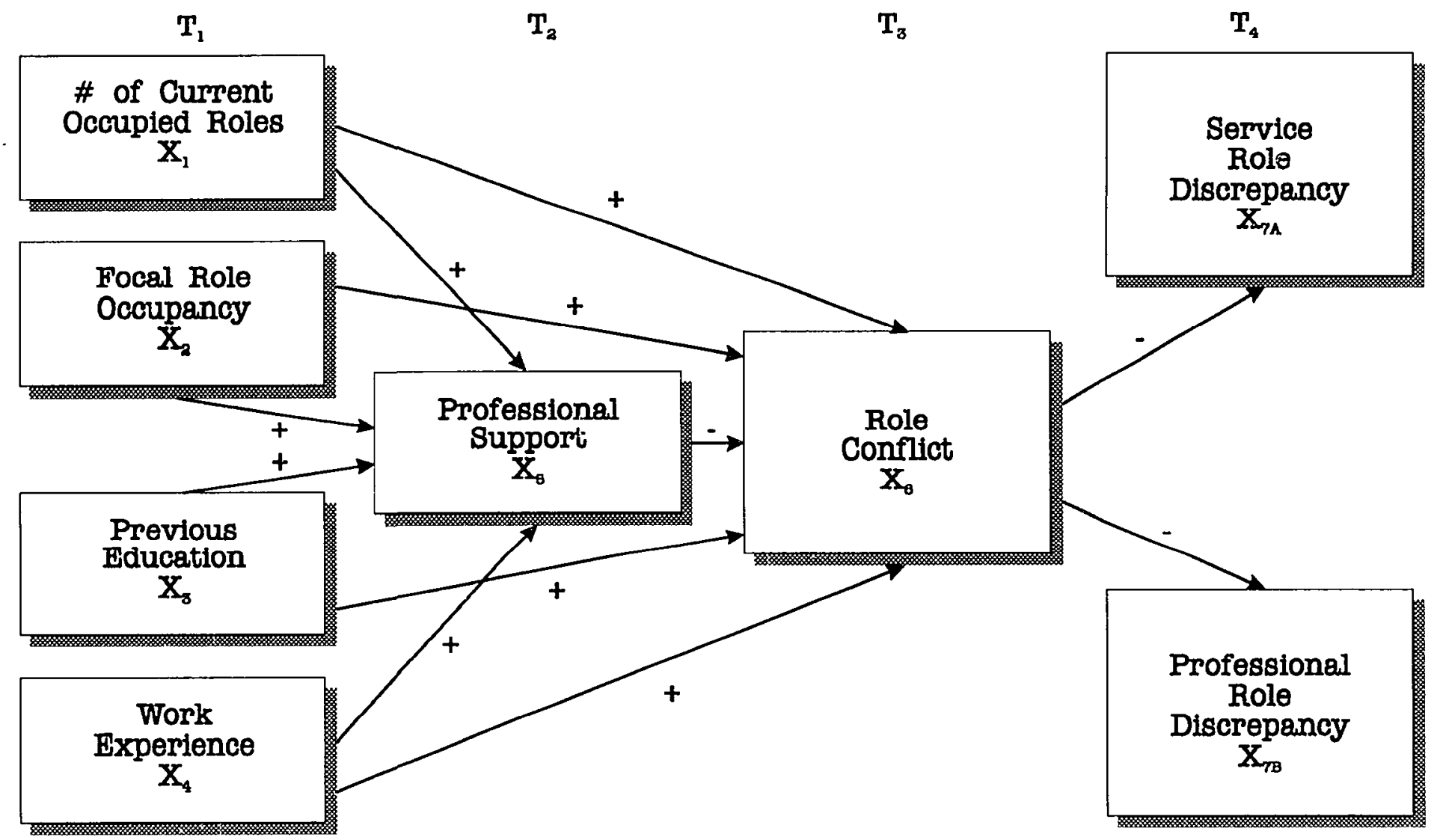

Proposed Path Model for examining the effects of exogenous variables and intervening variables upon the ease in role transition for re-entry students. 
Theoretical Definitions of Variables

1. Number of current occupied roles enacted by reentry student: Specific role tasks include those role functions within the family structure and all social roles that can be associated with adult status (Levinson, 1978; Williams, 1983). Roles of concern to this study are the spousal, parental, work, personal (self), and social interaction roles that are concurrent with the student role. Subjects will be asked to identify the number of occupied roles on the demographic data form.

2. Focal role occupancy: A role position or status that holds greater value and requires a higher degree of concentration and energy by the individual in order to meet expectations of that role at the expense of meeting the expectations of other occupied roles. Self-identity is frequently associated with the focal role, and the person may feel obligated to meet the demands of that role at all costs (Hardy \& Conway, 1988; Marks, 1977; Sarbin \& Allen, 1968). Subjects will state which occupied role is of primary importance on the demographic data form.

3. Previous education: Post-secondary school vocational preparation for a career in the health care field that is equivalent to 13-15 years of education. This education is obtained in lower-division educational settings. The majority of RNs have received career preparation in associate degree programs or in hospital 
schools granting a diploma credential. Military allied health care workers have learned through on-the-job training or short-term technical programs. This educational format is strongly influenced by the medical model with emphasis on learning application of technical skills rather than upon synthesis and abstract knowledge (Baj, 1985, June; Conway, 1983). Adult students may also have earned academic degrees in other fields that can influence subsequent learning. Subjects will identify the level of previous education on the demographic data form. 4. Work experience: Part time or full time employment in a staff/leadership/management position in a health care setting for one or more years. (Baj, 1985, June; Carroll \& Artman, 1988; Green, 1987; Uphold, 1983). Years of work experience and current work hours per week will be documented on the demographic data form.

5. Professional support: A type of formal social support that requires a special educational background for an individual to serve as a resource person for help with special problems. Professional communication skilis include listening, providing encouragement, reflecting trust and understanding, and unconditional access to the professional. Indirect problem solving behaviors include focusing communication directly on the problem, offering suggestions, referrals, and directions. Direct problem solving is the provision of knowledge and skills by the 
professional, monitoring of one's status over time, and intervention when necessary (Goldberger, 1987).

For purposes of this study, the professional support person will provide assistance in the socialization process, clarify role expectations, and be perceived as a mentor or role model, and resource person. Subjects will be asked to identify the person who has provided them with professional support while in the student role. The amount of perceived support will be indicated by responses to the Goldberger Professional Support Scale.

6. Role conflict: A complex umbrella term that describes the incompatibilities between role expectations and role functions. Conflict may occur as role overload due to multiple role involvement or when elements of a given role are unclear, incomplete, or contradictory. Conflict can be of intrarole (intrapsychic) or interrole dimensions. Role conflict is defined as an antecedent to role strain which is a perceived difficulty in meeting demands and expectations--an undesirable state within a role arising from stress associated with that role (Biddle, 1979; Kahn, Wolfe, Quinn, Snoek \& Rosenthal, 1964; Lambert, C. \& Lambert, V. 1988; Ward, 1986). The degree of role conflict as a reentry student will be demonstrated by the responses to the GrendelI Role Conflict Inventory (Grendell, 1987). An additional item 
on the demographic form requests the subjects to rate the degree of conflict as result of the student role.

7. Professional Role Transition involves a commitment to the profession and its goals which include emphasis on collegiate education, interest in continuing education, membership in the professional organization, and a sense of mission or humaritarian service (Corwin. 1968; Pieta, 1976). The concept of caring places a high value on the dignity and worth of every person. Accountability as the patient/client advocate is a major component of the professional nurse role. Additional dimensions of a profession are: autonomy, creativity, ethical behavior, and community sanctior (Urden, 1988). Role transition is a process that demonstrates acceptance and internalization of the tenets of the professional role into one's personal value system as demonstrated by the responses to the Pieta Role Conceptions Instrument (1976). The transition involves letting go of previously valued beliefs that were an integral part of the student's self-identity and taking on the new theoretical concepts of the baccalaureate curriculum. 


\section{Hypotheses}

Hypotheses for the investigation include the following :

1. The number of current roles enacted by the reentry student, occupancy in a focal role, the type of education, and work experience have a direct positive relationship on professional support provided by faculty.

$$
\text { (X1----> X5； X2----> X5； X3----> X5； } \mathrm{X} 4---->\times 5 \text { ) }
$$

2. The number of current roles enacted by the reentry student, occupancy in a focal role, previous education, and work experience have a direct positive relationship on role conflict.

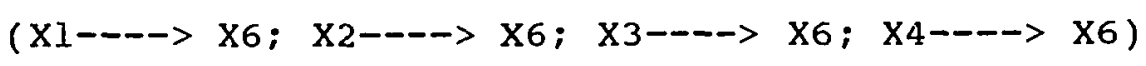

3. Professional support has a direct inverse effect on Role conflict.

$$
(X 4--->X 6)
$$

4. Role conflict has a direct inverse effect on transition to the professional role.

$$
(\mathrm{X6}---\rightarrow \mathrm{X} 7)
$$


5. Transition to the professional role is indirectly influenced by the number of current roles enacted by the reentry student, the occupancy in a focal role, the type of education, and work experience via professional support and role conflict.

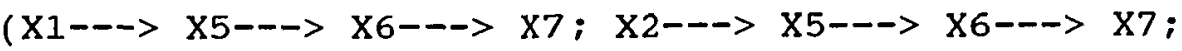

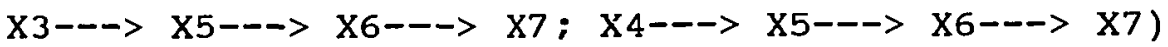

6. Transition to professional role is indirectly influenced by professional support via role conflict.

$$
(\mathrm{X} 5---->\mathrm{X6}---->\mathrm{X7})
$$

\section{Significance to Nursing}

Results of the 1988 national survey of the Registered Nurse population of 2.3 million revealed that two-thirds of the employed RNs work in hospital settings in staff level positions. Approximately $71 \%$ of these spend at least $50 \%$ of their time in direct patient care. The majority are female (97\%); seven out of ten are married, and 55\% have dependent children at home. More mothers with children under six years of age work part time than any other group. The average age of employed nurses is increasing with a range between 30 and 40 years. The number of RNs seeking advanced degrees has increased since the previous survey in 1984 (U.S. Department of Health and Human Services, 1990). 
Health care costs, which represent $11 \%$ of the Gross National Product, are predicted to rise to more than $15 \%$ by the year 2000 (Rapson, 1987). Authorities also predict there will be a need for $44 \%$ more nurses who will be prepared to provide home care to critically ill clients. These nurses will not be generalists, but must have a minimum of a baccalaureate nursing degree plus two years of specialty nursing (Zanca, 1990).

The advances in technology, the increase in the demand for readily accessible health care, the limitations placed upon health care by cost containment measures, and the inflation rates are factors having implications for nursing and nursing education. The greying of the population and unique needs of the elderly also place a heavy demand for available and expert nursing care. The skills gained through the professional degree are seen as effective measures in meeting the demands of the health care system expected by society and the nursing profession.

The nursing profession is also confronted with the challenge for providing solutions to the current shortage of active nurses which has been further compounded by the paradoxical exit of nurses from the work force and the decline in enrollment of high school graduates. Several authorities predict that these conditions will continue well into the 1990s (Rapson, 1987). 
These concerns have prompted nursing leaders to seek innovative ways to provide advanced education for adult reentry students, and to elevate the professional status of nursing (Edwards \& Lenz, 1987; Leddy \& Pepper, 1989; Schlotfeldt, 1981). The increasing number of $\mathrm{RN}$ and other adult reentry students in nursing programs suggest that this research is timely and necessary. One of the central themes of role theory is the negative affects of role conflict upon learning, decision making, and role transition. Several demographic and environmental factors that contribute to role conflict for the adult reentry student have been identified in previous studies. The model designed for this study depicts professional support as an intervening, or buffering, variable between the perceived role conflict and professional role transition. Testing of the model will help to clarify the interrelationships among the variables, and identify areas where supportive measures might be helpful. 


\section{Chapter II \\ Literature Review}

This chapter focuses on the relationship of predictor variables of the proposed model to each of the subsequent outcome variables. The discussion follows the temporal ordering of the model (see figure 1), and a summary concludes each section. Since professional support is a newly developed concept, much of the discussion of this concept is theory based rather than empirical. Suggestions provided by researchers that met the definition criteria of professional support were included in the discussion. Shane's (1983) study is used as the overview of the reentry student's perception of the returning to school experience.

Returning to school can be an exhilarating experience. The student is fascinated by the challenges associated with acquiring new knowledge, skills, and a promising future. Shane (1983) referred to this time as the honeymoon, the first phase of a series of positive and negative events that occur during the educational process that have been described as the Returning-to-School Syndrome. Shane's exploratory study was conducted over a six year period after observing general trends in the 
behavior and emotional crises experienced by reentry nursing students. Data collection from 50 RN students consisted of personal diaries, interviews, and seminar discussions. Faculty were also surveyed to elicit their observations of student behaviors. From these various sources, she has developed a theoretical model that consists of three distinct phases concerned with the resocialization of the reentry student. These phases are the honeymoon, the conflict, and recovery or conflict resolution. Her findings lend many insights into the events that occur as the adult returns to the academic environment.

The honeymoon usually has a short duration. Shane stated that the initial excitement diminishes as the demands of the academic role infringe upon fulfilling the responsibilities of one or more significant roles. The second phase is a time of conflict which is similar to culture shock or reality shock. This can be a time of turbulent negative emotions when the individual is faced with an unfamiliar situation without available resources to assist in the adjustment. The individual seeking career mobility through advanced education is particularly vulnerable to conflict when there are opposing expectations between the scholarly ideals of the academic environment and the technical or vocational emphasis of the previous education and work experiences. The 
individual must reevaluate role expectations and self-worth that are identified with the work role.

During the conflict state, many of the students in Shane's (1983) study expressed feelings of depression, fatigue, insecurity, sleep disturbances, and outbursts of anger as well as hostility toward the faculty and/or the curriculum. Withdrawal from the program was viewed as the ultimate hostile act.

Student reports of conflicts with specific role expectations in Shane's (1983) study included: (a) time constraints imposed on family responsibilities and the family's lack of understanding about the academic requirements (b) differences between realism of the work world and idealism of the educational environment (c) redundancy in information included in the prior educational setting and the current curriculum, and (d) perceived threats related to the faculty attitude and evaluation procedures. Faculty attitudes were particularly threatening when they communicated messages that forced students to reevaluate long-held values and beliefs.

The third phase of conflict resolution, or recovery, is a transition that occurs as the individual identifies with the new values without abandoning previously acquired and cherished ideals. This transition has been defined by Shane as biculturalism. Senior students in her study 
expressed a willingness to integrate the new learning into their self-identity as professional nurses. True resolution did not always occur, however. Shane observed two ineffective attempts commonly used by reentry students to minimize the effects of conflict. These were game-playing or false acceptance of the new ideals, and second, a chronic state of conflict and hostility where there was a vigorous defense of ego identity with the original role and a strong resistance to change. Some individuals vacillated from one phase to the other. Shane commented that some students completed the program equipped with knowledge, but without a major change in attitudes or beliefs.

The events described by shane concerned with the conflict and conflict resolution phases contributed to the development of the theoretical model for the current study which includes the variables of previous education and work experience as major influences on role conflict and potential barriers to role transition. Shane's research also provided the background for including the conflicts between the academic role and commitments to other social roles as variables in the current study. The conflicts related to multiple roles (constraints upon time and energy, traditional sex-role attitudes that influence primary roles, and conflicting expectations from multiple role partners) can induce role conflict and indirectly 
affect role transition. The additional demands of the academic role frequently compete for the person's attention to family, partner, work, social, and personal roles. The questionnaire developed for this study includes these five dimensions.

Shane (1983) also commented on the need for sensitivity of faculty to the role conflicts experienced by returning students. The presence of faculty members who have bicultural values was considered to be crucial to successful transition. Students in Shane's study reported greater confidence in their role performance when they were in contact with and supported by faculty who respected them as individuals and were sensitive to their unique needs. This support consisted of a faculty advocate and trusted counselor, a valuing of the student's previously acquired knowledge and experience, and a transition course where complex issues could be explored. Social support from peers, co-workers, friends, and family was also beneficial in alleviating stress.

Professional support has been included in the current model as a buffering variable between the background characteristics of the reentry students as contributing factors in role conflict, and as an indirect positive influence on role transition. The stresses experienced by reentry students are important issues to educators as more adults choose career advancement through additional 
education. The organizational framework for this chapter is comprised of the linkages of the proposed theoretical model.

Relationships of Multiple Roles, Professional support, and Role conflict

Roles have been described as relatively fixed positions accompanied by socially defined expectations and demands by the structuralism branch of role theory (Hardy \& Conway, 1988). The difficulties in juggling multiple roles by women has been studied extensively by sociologists. Depression has been associated with multiple role involvement, particularly for the working mother when there has been no reassignment of family responsibilities and for the single parent who lacks support resources (McBride, 1988, 1989).

Green (1987) offered a multi-dimensional profile of the mature RN learner. The majority were women within the age range of 20 to 50 years and were involved in three to five major life roles of family, work, and social activities. These roles require extensive time and emotional commitment that do not subside with the addition of the student role which brings added pressures and the potential for conflict within and between the other roles. Constraints upon time and energy were cited as the most common stresses. Typically there had been a lapse of several years since previous schooling, and most students 
were anxious about study skills. Green cited several areas where faculty support assisted in the transition to the student role, and promoted a positive learning environment. Providing time for discussion of academic shock, and identifying resources for survival skills, flexibility in curricular scheduling, and individualized learning experiences were some of the ways in which faculty provided support.

These recent findings did not differ significantly from earlier surveys conducted in the 1970s. Hillsmith, (1978) found that the majority of reentry students attended school part time due to multiple role responsibilities, and many felt that they had received little encouragement or support from their spouses as they pursued their education. Zorn (1980) stated that most of the non-traditional students continued to work while attending school, and also remained involved with community activities such as parent-teacher associations, the Red Cross, and teaching CPR or child-birthing classes. Many of the students preferred part time evening classes and were unwilling to relinquish their other roles.

The faculty surveyed by wooley (1978) reported high anxiety levels in students during their adjustment to the academic setting. Approximately one-third withdrew from the program during the first year citing frustration over loss of control of their lives, and the constant need to 
set priorities that were often incompatible with other major obligations. Health status, family crises, and general disillusionment were given as reasons for leaving. Wilson and Levy (1978) reported that the amount of perceived support in managing these stresses was crucial in the adjustment to the student role.

In a comparison study of $\mathrm{RN}$ and generic nursing students, Baj (1985) reported that $82 \%$ of generic students were enrolled as full time students; whereas, only $40 \%$ of senior level RN students attended school full time. Approximately one third of the returning students were graduates of diploma programs, and the average time for completing the advanced degree program was 11.2 years. Some of the stress indicators reported were the number of occupied roles, financial status, amount of work hours, major life events, illness in the family, and the number of dependents. The family structure of the RN group had greater diversity and a greater number of dependents. They had experienced more major life events than reported by the generic student group. However, despite the higher percentage of multiple roles and the higher number of work hours, the RN students were able to maintain a grade point average only slightly below the generic students ( 3.16 vs. 3.33$)$.

Similar findings were reported in the research by Jackson (1984) who stated that students often resented the 
conflict between study, work, and their desire to be with family and friends. Orientation programs, development of peer support groups, and counseling services by faculty were suggested as methods for providing assistance in the resocialization process.

Married students and women with children reported the greatest number of stresses as result of the additional student role in a studies by Carroll and Artman (1988) and Menger (1988). The necessity for compromising family responsibilities, worry over child care, and work schedules were major problems. Seventy percent of the RN students stated they worked 31-39 hours per week, and $80 \%$ had dependent children (Carroll \& Artman, 1988). Multiple roles, self-esteem, employment, and spouse support were significantly related to role strain perceived by subjects in Menger's study.

Although returning to school was a personal choice, many adult students felt guilty for sacrificing the needs of the family to meet their own personal goals (Murdock, 1987). Many of the returning students included in a study conducted by Rothert, Talarczyk, Currier-Jayne, and McCartney (1988) were not eligible for financial assistance, and therefore, needed to continue working to pay for school expenses as well as meeting the needs of the family. Counseling was mentioned as the most helpful measure in student decisions to return to school and with 
the adjustment to the student role. Most of the students were extremely motivated to do well, but were also concerned that they would not meet their highest potential in academic achievements due to the constraints of the other roles.

These conflicts are not unique to nursing as illustrated by the research of Beutell and Greenhaus (1983) on married women students enrolled in general college courses, and by the studies of Kopelman, Greenhaus, and Connolly (1983) with men and women involved in multiple roles. One of the most frequently mentioned sources of stress was the competition between different role expectations upon time and energy. The majority of the subjects reported one or more conflicts between home and non home roles.

The researchers also found that women married to men with traditional sex-role norms experienced the most conflicts. They suggested that the women probably continued to carry the major responsibility for child rearing and household tasks in addition to their work and/or student roles. A common strategy for coping with these conflicts was to assume the super woman role in the attempt to meet the expectations of all roles. This seemed to be particularly true for women who, also, had traditional sex-role attitudes. 
Problems associated with the work role have frequently been studied in isolation from the rest of life experiences (Kopelman, Greenhaus \& Connelly, 1983). The authors cited the need for understanding the relationship between work and family lives due to the current changes in career values and the increase of dual-career couples. They also noted that tools used in assessing role conflicts have not been consistent from study to study. Their research focused on the definition of concepts and the development of an instrument to measure the conflicts within each of the domains of work and family roles, and the conflicts between the two roles.

In their study of male and female college students, the researchers found a greater amount of family role conflicts for individuals who were married and employed full time. In addition to their own multiple roles, the group also had a higher percentage of spouses who worked. This would inevitably affect the family and home responsibilities.

The instrument developed for the kopelman et. al. study was useful in formulating items related to family, work and interrole conflicts experienced by reentry nursing students. The instrument was also used in the pilot study as a validation tool for the Grendell Role Conflict Inventory (1989). 
Summary

The previous discussion has provided a comprehensive profile of the adult student which has not altered considerably during the past 10 to 15 years. The majority of role conflicts (role overload) were concerned with constraints on time and energy. Respondents reported a range of three to seven occupied roles related to family, work, social, and self as a self-actualized person. The addition of one role necessitated compromise in the other roles, often leading to role conflict, frustration, dissatisfaction, and anxiety or tension.

Adult students reported conflicts related to a sense of powerlessness in the student role, child care worries, diminished relationships with family and friends, fear over the ability to excel due to multiple role obligations, and financial concerns dictating the need to work. Several expressed guilt over placing self-gratification needs for additional education above other role obligations. A particular concern was a fear of neglecting the requirements of the parent role.

All studies demonstrated that perceived role conflict was detrimental to taking on the student role. Two of the studies which were taken from the social science literature, have discussed multiple role conflicts for both men and women. The results are supportive of the exemplars from the nursing literature. All of the studies 
have provided a background for the development of the role conflict tool used in the current study with reentry students.

The positive effects of professional support upon conflict resolution were suggested as the supportive attitude, counseling, and information provided by faculty in helping the students' adjustment to the academic environment. Lack of support from family members, peers, friends, and faculty was viewed as a deterrent to coping with stressful events.

This section has primarily been concerned with the functional/structuralism branch of role theory. The traditional scarcity hypothesis states that role conflict and role strain are inevitable as multiple role expectations compete with one another for the individual's inherent resources of time and energy. The influence of traditional role expectations was introduced as an intervening variable by Kopelman, Beutell, \& Greenhaus (1983). Intervening variables can alter an individual's perception of the situation and subsequent behaviors. Relationships of Focal Role commitment, Professional Support, and Role conflict

Marks (1977) referred to role commitment as a source of energy for role involvement and satisfaction. The individual who is committed to a given role often forsakes other obligations in order to meet the expectations of the 
focal role. Self-identity and role are very closely aligned. The expected role behaviors are learned through interaction with others within a social structure. Commitment, involvement, and satisfaction with role performance are greater when self and role are congruent (Sarbin \& Allen, 1968).

o'Shea (1982) stated that the individual's role orientation is associated with the predominate role, whereas Callero (1986) described role as a dimension of the self. The unique perspective of each individual unifies the concepts of social status, identity, and role, thus defining the expected behaviors and providing an idealized conception of the self in a given role.

Adult social identity is related to the ascribed roles such as male or female, adult, parent, and wage earner. Self-identity with a role occurs over time and emerges through interaction with others. Each contact has the potential for modification of behavior. Social sanctions and non-complimentary labels are frequently given to those who do not conform to societal expectations (Sarbin \& Allen, 1968).

The person involved in multiple roles can use negotiation to resolve conflicts; however, role orientation, or commitment, is more difficult to change. The role which violates the person's self-concept, or that is unbecoming to self-esteem, often results in 
psychological and somatic symptoms. Tension, cognitive strain, and decreased performance were reported by individuals who were asked to perform dominant or submissive role tasks that were incompatible with their role orientation (Sarbin \& Allen, 1968).

Each role can be viewed as a potential drain on an individual's scarce resources or as a potential for enriching one's life (McBride, 1989). The three indicators of role conflict in McBride's study were (1) family roles that required predominantly feminine characteristics and work roles that had primary male characteristics (2) perceiving general conflict during the past year, and (3) discrepancies between satisfaction with a role and the importance or centrality attributed to the role. High depression scores were associated with all three indicators suggesting that the significance of a role has a greater influence on role conflict than multiple role involvement.

The following studies have been chosen for the discussion of potential conflicts related to the particular, or focal roles, of the reentry student. Gender Role. Due to sex role socialization, men usually do not consider nursing as a career; and role strain has frequently been reported by those who have entered the predominately female profession (Johnston, 1987). On the other hand, Meleis and Dagenais (1981) 
noted that sex-role socialization of women emphasized commitment to family and home responsibilities rather than seeking a career. The working role as a nurse was viewed as a secondary or temporary role that could be scheduled around the responsibilities of wife and homemaker. Bueche (1986) found that the majority of returning female students experienced guilt and anxiety over their pursuit of personal achievement rather than remaining with traditional feminine roles.

Adult Role. Much of the adult role identity of the subjects in Baj's (1985) study was associated with being in control of personal decisions and life style. The return to the passive student role, when perceived as a threat to the self-image and self-esteem, resulted in a feeling of powerlessness. She cautioned that educators must be responsive to their unique needs, and help to minimize the threat to the adult's self-identity.

Beeman (1988) and Merritt (1983) noted that adult students expressed feelings of frustration because their maturity and styles of learning were not considered to be different than the characteristics of the younger and inexperienced generic students. They wanted to be recognized as equals in interrelationships with counsellors and teachers and resented the authoritarian faculty figure. Rendon (1988) reported that although the student role was alien to the adult self-image, the 
individual who had a more compliant personality made an easier adjustment.

Parent Role. Research on dual roles of modern women has emphasized the role of wage-earner as a secondary role to that of mother and homemaker (Baruch \& Barnett, 1986). The potential for role overload, role conflict, guilt, and anxiety was greater when the various role demands were incompatible; however, the researchers found that self-esteem has been associated with the work role even though the woman was required to juggle several roles. Their earlier research findings (1985) indicated that the value attributed to a particular role was an important aspect in meeting role demands; however, the quality of similar roles experienced by two individuals often differed.

Barnett and Baruch (1986) examined role quality, multiple role involvement, and psychological well-being of women in diverse family role patterns. An instrument was designed to measure the quality or balance between rewards and distressing aspects of each role. The three indices of self-esteem, pleasure/satisfaction, and depression were used to indicate levels of well-being. The scores indicating rewards, or quality, for all roles were consistently higher than role distress scores thus yielding positive mean balance scores. 
Significant relationships were found between role conflicts and occupancy of the parent role, and between conflicts and quality of work role. The role of parent was found to be the major source of role overload and conflict.

Similar findings were reported by Holahan and Gilbert (1979) in their research with dual career couples. The authors predicted that higher stress levels would be reported by persons highly committed to both parent and professional roles--roles with contradictory expectations. They also predicted that career women who had children would experience the greatest amount of conflict, citing that cultural norms and values had not changed rapidly enough to lend full support to dual-career families. In general, they commented, aspirations toward a career have been negatively related to role conflict for men, but positively related for women.

Their predictions were partially supported. Both male and female parents reported a greater number of conflicts related to their commitment to professional and parent responsibilities. The researchers suggested that sex-role attitudes of the partners were factors in meeting role expectations. The couples in the study reported a high level of career commitment, high self-esteem, mutual support, and satisfaction with life. The results indicated that some individuals had a serious commitment 
to more than one major role and did not experience role strain.

In a later study, Gilbert and Holahan (1982) investigated the coping strategies of returning male and female adult students as they encountered conflict between their student/professional roles and their parental role, or with their personal roles as self-actualized persons. Regardless of the coping strategies used, women reported more conflicts, particularly related to the parent role. Work Role. Woods (1985) examined the relationship of employment on the mental health of young married women. Women who were committed to traditional sex-role norms neglected their own personal needs in their attempts to resolve role conflicts, often accommodating their careers to match with family responsibilities. Women with modern sex-role attitudes were more likely to negotiate with role partners for help in meeting role obligations.

Nontraditional sex-role attitudes seemed to serve as a protective measure against poor mental health for women who were involved in the three major roles of spuise, mother, and wage-earner. However, the study findings revealed that lack of support lead to depression for women involved in multiple roles.

Student Role. Campaniello (1988) stated that returning to school is considered to be a major role transition and has become a common occurrence during the 
past few years. Campaniello examined the effects of multiple roles, sex-role orientation, social support, and perceived role conflict of reentry female nursing students. The occupancy of a certain role had a greater influence on role conflict than multiple role involvement. Although there was a high potential for role conflict, respondents commented that the stimulating effects and pleasures derived from returning to school outweighed the disadvantages. Respondents did not consider traditional role expectations as standards for role performance; however, the parenting role was rated as the most important role and having the greatest potential for conflict.

Campaniello (1988) also found that sex-role orientation was related to a feeling of well-being. The very nature of the baccalaureate curriculum that promotes autonomy, critical thinking, and independence was perceived as more threatening to the woman with traditional feminine sex-role attitudes. Social support was influential in reducing role conflicts. Anticipatory socialization was mentioned as a means for lessening the concerns related to the student role.

Bardossi (1980) reportec̄ that recurning Rivs ranked their primary commitment to the family role, the job was given second priority, and the school role was given the least importance. Whelan (1984) who viewed role 
orientation as a dynamic process, noted that the facilitator/counseling role of the faculty member was influential in the process of changing roles and attitudes as adults returned to the academic setting. She also emphasized the need for faculty who are sensitive to the unique needs and role commitments held by the returning students to assist them with problem-solving, and to encourage the formation of support groups.

Summary

The relationship between commitment to a focal role and the potential for role conflict is an important aspect in understanding the unique characteristics of the reentry student. Several of the previous studies have demonstrated that the majority of conflicts were associated with the parenting role and identity with traditional sex-role attitudes. The willingness of the male partner to move away from traditionally assigned roles was perceived as helpful in coping with conflicts related to family responsibilities as more dual-career family life-styles emerge.

These studies have also shown that identity with the adult role was contradictory with the normally passive student role. Adults expressed frustration and powerlessness. Psychological and somatic symptoms correlated with conflicts. Items on the role conflict inventory to be used with reentry students that reflect 
this potential problem area are included in the self-role dimension.

Suggested indicators of professional support were the recognition of the unique needs of adults and the use of adult learning strategies. Anticipatory socialization, counseling, and suggesting the use of peer and social support groups were also mentioned.

The growing trend toward career advancement through education for adults and life-long learning indicates the need for further research to identify areas of conflict related to the focal role and methods that will facilitate conflict resolution.

Relationships of Previous Education, Work Experience, Professional Support, and Role Conflict

Conflicts between previous education and work experience with the student role are integrally related. Socialization to the occupational role is one of the most significant events in the life of the adult (Kramer, 1974). Adult self-identity is defined by the occupied social roles, and competent performance in the work role is particularly valued. The work setting serves as a strong reinforcement to the knowledge and philosophical values acquired during the prior learning experiences. Rather (1990) reported that little research has included the perceptions of reentry RN students regarding what they have found to be meaningful experiences. A 
major finding from her phenomenological study was that returning students could not separate their knowledge gained through nursing practice from their learning experiences. Experience had become a way of thinking or understanding all aspects of their nursing world.

The discrepancies between the philosophies of the previous educational program and the baccalaureate program were major concerns to reentry students. The emphasis on theoretical concepts, decision-making, and autonomy in the baccalaureate program caused confusion and frustration for individuals who had been functioning in the work environment using a different set of skills.

A study conducted by Schoen (1982) indicated that $84 \%$ of the nurse respondents disagreed with the requirement of the baccalaureate (BSN) degree as the entry level into practice. For some returning RN students, the BSN was perceived as only an obstacle to overcome in order to gain career mobility (Bardossi, 1980).

Jackson (1984) reported that an individual's age and years of experience contributed to a greater number of barriers to the transition to the student role. Low confidence in one's own learning capabilities was an additional concern. Students also had difficulty in seeing the relevance of the curricular content to the clinical practice, often finding the decision-making models too complex and time-consuming. When they did 
attempt to implement the newer concepts in the work place, they were frequently confronted with resistance from co-workers and administrators.

The degree program was not perceived as being helpful in their present work position, but solely as a means for career mobility. This finding suggested the need for highly qualified clinical instructors to serve as role models and to emphasize the importance of direct patient care. Further studies on strategies to meet the students' learning needs, and the needs of faculty working with non traditional learners were also suggested.

Frustrations reported by returning students in Green's (1987) study included concern with the entry requirements into the university system, the failure of recognition for past achievements, conflicting advice from advisors, difficulty in securing financial aid, and rigidity in curricular structure. Students also found the various activities involved with the student role required coordinating schedules, juggling roles, and were overly demanding of time and energy.

The resocialization process that challenged the previous education and work experience was particularly threatening to personal and professional identities. Expressions of disillusionment, hostility, anger, high anxiety, and criticism of others in the learning environment were mentioned. Tension in family life was 
also high. The students did not necessarily understand why they were emotionally upset, and some individuals experienced difficulty in maintaining a clear perspective during the first months of their schooling. The need for practical and emotional support was suggested.

The degree of role stress was strongly influenced by the type of work experience and the length of time in the work role. The conflicts were further accentuated when the student continued to work in institutions where previously acquired knowledge and skills were valued. The reentry students considered themselves to be professional and believed they should be granted full articulation privileges, and be given recognition for their clinical expertise (Green, 1987).

The need for clarifying expectations of the professional role was suggested by Beeman (1988) who conducted a comparison study of baccalaureate programs in meeting the adult learning needs. Several of the respondents reported conflicting feelings about the need for the advanced degree. Subjects were requested to rate the effectiveness of their program in providing access to self-directed learning, opportunities to build upon prior knowledge, and availability of support during the learning process. The RNs enrolled in generic programs indicated greater frustration levels than students in specially designed programs. 
Comparable findings were presented by Baj (1985) and Lee (1988) who questioned the appropriateness of traditional programs for returning RNs. These programs which were designed for entry-level students seldom acknowledged the experience and previous education of the returning student. Many RN students reported frustration with the repetitious learning activities and felt that the additional education was a waste of time (Beeman, 1988).

Approximately one half of the respondents in Rendon's (1988) study expressed that prior learning and experience had not been valued. One third believed they had greater competence in clinical skills than their faculty. However, sixty-one percent stated they felt overwhelmed by the requirements of the student role. Most of the dissatisfaction occurred during the first semester. Rendon suggested that students would greatly benefit from anticipatory guidance before entering the program.

The surveys conducted by zorn (1980) and Rothert, et. al. (1988) indicated that reentry students preferred part time study, flexible scheduling or courses scheduled into blocks of time to accommodate their work schedules and home responsibilities. The majority of these students worked in hospitals, were married, and had children. Financial concerns and anxiety about returning to school as well as the difficulties in managing multiple roles were reported as major obstacles. 
Most of the students had not attended a large university, which, in itself, was considered to be an intimidating experience. Rothert, et. al. (1988) reported that $21 \%$ had completed their initial nursing programs before $1960,38 \%$ in the 1970s, and $41 \%$ since 1980 . A wide range of work experience and job descriptions was represented by the subjects in the study with varying degrees of commitment to the value systems associated with the previous education. The degree of commitment was often influenced by length of tenure, work specialty area, and level of work responsibilities. These results suggested the difficulties involved in discarding cherished values and adjusting to a new philosophy. Faculty who responded to a survey of generic baccalaureate programs conducted by Blatchley and stephan (1985) indicated their uncertainty about the methods that would facilitate the transition to the student role of the reentry students. They expressed many frustrations in working with this group of students who presented different needs than those of the traditional students. Several educators requested a report of the study findings that might assist them in planning curriculum. Several of the reporting schools had implemented a transition course to help bridge the gap between technical and professional orientations, and assigned one faculty member as advisor and/or counselor to assist the adult students. 


\section{Summary}

The positive relationship of previous education, along with work experience, and role conflict are considered to be principal components of the proposed model. The studies exemplify additional research findings suggesting that prior education and work experiences can influence the attitudes of reentry students. Most of the identified conflicts were related to the differences in philosophical orientation of the technical and professional schools. The major conflicts included frustration and anxiety associated with the admission and testing procedures, the student's commitment to the tenets of their prior education, and the resistance to change. Commitment was frequently related to years of experience and level of work responsibilities.

The unique qualities of this group have been represented by the diversity in background experiences among the individuals. The devaluation of prior learning and work experiences were perceived as threats to the adult's self-image as a practicing professional. The stresses imposed by the student and work roles have also been included in the previous discussions of multiple and focal roles.

All of the study reports have been published in the 1980s, and are representative of current issues. These findings suggest the necessity for the individualized 
assessment of learning needs and measures to assist the student in accepting the values of the professional curriculum.

Suggested professional support mechanisms included flexibility in course schedules, recognition of the students' anxiety about returning to school, facilitation of the admission process and challenging procedures, and structuring the curriculum to more accurately meet the needs of the adult learner.

Acceptance of the students' acquired knowledge and work experience was a major factor in reducing anxiety, anger, and frustration. A transition course implemented by several schools was mentioned as an effective means of helping in the adjustment phase. The counseling provided by a faculty advisor with bicultural attitudes was also viewed as a influential factor to lessen role conflict. Relationships of Professional support, Role Conflict, and Role Transition

The influence of professional support on role transition has not been studied in depth. The majority of research in this area has been subsumed under social support frameworks. Gottlieb (1983) posited that professional support is a specialized form of social support. He proposed that professional support is an effective means for mobilizing psychological resources, mastering emotions, and in providing tools to assist 
individuals in meeting situation demands. The professional support person initiates the formation and development of support. Through working with groups and fostering or strengthening group relationships, the professional provides the network for interaction. Professional support may be unidirectional and is most useful during major transitions or crises. The goal is to enable the individual to form his or her own social support system (Norbeck, 1981). In Norbeck's model, support may be most effective when it is provided by a key network member, such as a self-help or cohort group, spouse, or professional.

Support groups, or reference groups, have been identified by Norbeck (1981) and Weinert and Brandt (1985, 1987) as cornerstones of social support. Such groups have been proven effective in buffering the effects of events such as life transitions, social readjustment, and depression (Gottlieb, 1983). Weinert and Brandt found that self-worth was affirmed within groups that had common interests and values. The anticipatory socialization provided by the professional and the support groups can be beneficial in the transition process.

Role transition is a process of moving in and out of social roles. It may involve the addition or termination of a role without affecting the other occupied roles or may necessitate leaving one role in order to take on 
another. Role transition has frequently been referred to as a crisis event. However, transitions can occur so naturally that the individual is not immediately aware of the changes (Burr, 1972).

Several role transitions related to nursing education are the taking on of the initial or reentry student role, progression through the educational program, graduation, and entry or return to practice. The following studies are brought together for the discussion of the relationship between professional support, role conflict, and professional role transition.

The literature contains conflicting reports as to the buffering effects of social support on stress (LaRocco, House, and French, 1980). The researchers indicated that no specific clarification of constructs has been established, thus the measures of support among the different studies may not be accurate measurements of support. The purpose of their research was to construct a clear-cut model that could be applied in the reanalysis of previous data from three studies of work role conflict. Instrumental support, emotional empathy/understanding, and provision of information were defined as three different forms of social support. The model proposes that social support has a buffering effect on one's perception of job stress and job-related strain or dissatisfaction, but does not alter the main effects of job stress or job strain. 
Brief, Aldag, Van Sell, and Melone (1979) examined the role stress experienced by general duty nurses from diploma, associate degree, and baccalaureate programs. The researchers predicted that role stress would vary with the type of education and that the levels of stress would be related to job satisfaction. An instrument was designed to identify the type and frequency of activities performed in a typical hospital setting that were related to direct and indirect nursing care. No significant differences in task performance related to educational preparation were found, thus implying that job responsibilities of the staff nurse do not vary by type of education.

The investigators selected the role conflict and role ambiguity scale developed by Rizzo, House, and Lirtzman (1970). The results indicated that a higher level of stress was perceived by graduates from baccalaureate programs than by diploma or associate degree graduates. There was a significant negative correlation between job satisfaction and role ambiguity and role conflict. (The role conflict tool developed by Rizzo, House, Lirtzman also served as the basis for item construction in the Grendell Role Conflict Inventory.)

Brief et. al (1979) concluded that the role expectations originated in the educational setting were not substantially changed by extended contact with the 
work environment. They suggested that the under utilization of the educational skills of the professional nurse may have been a major factor in job dissatisfaction. on the other hand, the technical education was positively reinforced by the work setting.

These findings can be helpful in understanding the role stress experienced by the reentry student who continues to work while attending classes. Role transition, or role management, is a final stage of the resocialization process that may not always be complete. These findings also support literature claims regarding reentry students progression through the professional program without a major change in attitudes (Hiraki \& Parlocha, 1983; Muzio \& Ohasi, 1979).

According to Lynn, McCain \& Boss (1989), professional socialization is the most crucial issue in nursing today. The resocialization of the R.N. (and other health care providers) should be a major concern for nurse educators. They suggested that Symbolic Interaction Theory (SIT) be used when planning resocialization of reentry students. This perspective, which honors the reentry students' substantial knowledge and experience, may provide educators with a clearer understanding of the students' interpretation of what the nursing role is or should be. Their comparison study of generic and reentry students' views of the nursing role was conducted over a 
five year period. The Professional Orientation Scale and a six-dimensional scale of nursing performance were administered to the students upon admission and near to their graduation point. Scores from a referent group of faculty members were used to weight the student responses. A significant difference in group program entry scores indicated that $\mathrm{RN}$ students brought a greater knowledge of nursing and professional role orientation into the educational setting than the generic students. However, upon completion of the program, there were no significant differences between group scores, although the scores for the generic students had increased significantly and were more in alignment with faculty views. These findings suggest that the less-experienced generic student is more receptive to the molding by faculty, and that reentry students may not have seen the necessity for changing their views.

The research conducted by corwin (1968) has a classic place in the research literature on role conflict in nursing roles. Corwin's study was centered around the possible discrepancies between loyalty to professional, bureaucratic, or service concepts. Role transitions were referred to as turning points that involve a reassessment of the role expectations and of self-identity. The three dominant themes that are associated with the definition of nursing--an office, a profession, and a calling--were 
interpreted by corwin as the bureaucratic, professional, and service orientations. He stated that the values related with each concept can be held concurrently, and at varying degrees by individuals or groups. The differences among these beliefs can often result in conflicts of loyalty to one or more of the ideals.

The purposes of Corwin's study were to examine the influence of the type of education on the transition to the career role, and the influence of the work setting on the role orientation of the employed nurse. The subjects included staff nurses, head nurses, and students from diploma and baccalaureate nursing programs who responded to the questionnaire designed to measure the three orientations of bureaucratic, professional, and service orientations.

The results indicated that baccalaureate degree nurses tried to combine the values of bureaucratic and professional concepts. Their orientation to the service concept decreased with the partial acceptance of bureaucratic principles, while professional values were still maintained. Corwin (1968) concluded that the influence of the work setting caused the degree nurse to modify role expectations somewhat. The responses of diploma graduates revealed higher scores on the bureaucratic scale and lower scores on the professional scale. A comparison of the groups of students and 
graduates from diploma schools indicated that allegiance to professional concepts decreased after graduation while the initial loyalty to the hospital was maintained.

Although the age of Corwin's study must be considered, many of the findings appear to be relevant to today's reentry nursing student. These findings support the comments of Brief, Van Sell, Aldag and Melone (1979) that the initial education and socialization of the work setting have a powerful influence on the individual's role conception.

Kramer (1974) used Corwin's instrument in her landmark study of the reality shock experienced by new baccalaureate graduates as they entered the practice setting. The discrepancies between academic and bureaucratic ideals were seen as contributing factors to the frustration and disillusionment, frequent job changes, and different career choices. In Kramer's longitudinal study participants in the anticipatory socialization course experienced less role deprivation, did less job hopping and remained in their first job for a longer period of time than non-participants. There was also a greater bureaucratic orientation as well as a strong professional role conception as evidenced by the scores on the role conception scales. Her study has been the basis for many changes in nursing education and practice settings. 
Corwin's instrument has also been used in the study of student perception of role models (Whelan, 1984); role transition of nurses into specialty areas (Lewakdowski \& Kramer, 1980); role orientation of reentry students (Green, 1988); and a comparison study of professionalization of the ADN, BSN, and RN/BSN graduates (Lawler \& Rose, 1987).

Pieta (1976) used Corwin's instrument as the basic framework for the development of her role conception tool used in a comparison study with seven groups of nurses. The instrument was administered to female nursing students in the three types of nursing programs, (Diploma, ADN, and Baccalaureate) their respective faculty, and head nurses in acute care hospitals. The perceptions of each group as to the ideal role of nursing, the actual practice of nursing, and discrepancy, or the difference between the two roles, were examined. The study also compared the same perceptions across groups.

Pieta defined the ideal role conception as the perceived expectations of what should exist in nursing practice. The actual role conception was defined as the respondents' perception of what was practiced in the nursing role. Situational items were placed within the bureaucratic, service, and professional role conceptions.

The following statements are a summary of her findings that are of particular interest to the current 
study: 1) The traditional service role conception was considered by all groups to be the ideal nursing role. 2) professional role conception was the second ideal role, with the bureaucratic role conception being the least ideal. 3) students in the three educational programs expressed similar views as their respective faculty, however to a lesser degree. 4) Head nurses indicated less discrepancy with the bureaucratic role conception, and felt that the service role was practiced to a greater extent than any other group. 5) Scores of diploma and ADN students on the bureaucratic role conception scale were closer to the head nurses than any other group. 6) Baccalaureate faculty experienced the greatest discrepancy scores for all three role conceptions.

Pieta commented that previous studies have shown faculty to have a powerful influence on the role conceptions of students. Faculty viewpoints from the different types of educational programs may often differ from each other as well as differing from the role conceptions held by nursing administrators and their expectations of new graduates. The philosophy of educators is directed toward the ideal, or what nursing actions should be done, whereas the nursing aủininistrator is more concerned with efficiency and the needs of the organization. Discrepancy occurs when the person 
perceives differences between idealized actions and what is believed to actually occur in the practice situation.

The instrument has been used in several studies during the past ten years, including the investigation of professional and bureaucratic role conceptions and moral behavior among nurses (Ketefian, 1985), sex-role identity and professional role discrepancy (Forrester, 1983), and role orientation/socialization among nursing students (Bellinger, 1988).

Additional studies reviewed by this author include: A comparison study of role orientation, accountability and descriptive variables of hospital and supplemental agency employed nurses (Pierce, 1981); and nursing role conceptions, restructuring ability, and integrative resolution of nursing care dilemmas (Burrows, 1982). Pieta's instrument has been selected to measure the professional role transition of the reentry students in the current study.

In a cross-sectional study, whelan (1984) found Senior level reentry students had a stronger professional and service orientation with less bureaucratic allegiance than the newly enrolled reentry students. A modified version of Corwin's (1962) instrument by Bevis (1973) was used. She proposed that role orientation is a dynamic process which can occur through planned cognitive, psycho-motor, and affective experiences. 
The professional subscale of Corwin's tool was used by Lawler and Rose (1987) in a comparison study of senior generic BS students, senior AD students, and senior RN/BSN students. They found a difference in the professionalization of nursing graduates prepared at the different educational levels. Generic students tended to be more idealistic in their responses, whereas there was greater role congruency between the ideal and actual professional role behaviors for the RN/BSN students. It was suggested that the work place has a greater socializing influence on the professional role orientation than was previously considered.

Estimates of ADN nurses who intend to continue their education toward the baccalaureate degree range from $51 \%$ to $70 \%$ (Lawler \& Rose, 1987). However, most nurse educators have the same outcome expectations of these students as from generic students. The researchers suggested that the graduating $\mathrm{RN} / \mathrm{BSN}$ was a more professional product than the generic or ADN graduate. The positive effects of support have often been mentioned in the literature concerned with the problems of the reentry student. This construct has been included in the model for this study as the professional support provided by one or more faculty members. The role of the educator is very important, particularly during the initial transition to the student role. Counseling 
provided by the faculty was mentioned as the most helpful measure during the adjustment phase (Beeman, 1988; Murdock, 1987).

Researchers also found that there is a need for more flexibility in the structure of the educational program in order to meet the needs of adult students, (Blatchley \& Stephen, 1985), and emphasis on the facilitative role of faculty in promoting professional growth and creativity (Carroll \& Artman, 1988; Lambeth, Volden \& Oechsle, 1989).

Lewandowski and Kramer (1980) stated that faculty can help students to recognize that conflict is a necessary part of change and transition to the professional role. Some forms of conflict can be healthy, creative, and be a potential for growth. Faculty members are important role models while the student is in school; however, the nurse who demonstrates expertise in the clinical setting takes on a new importance as the student nears graduation and anticipates joining the practicing group. A nurse educator who has bicultural attitudes can be the most effective of all role models (Green, 1988).

Some authorities believe that there will not be a vast change in behavior upon completion of the baccalaureate program. Professional commitment cannot be expected over a two to three year period, but requires extended periods of time (Frisch, 1987). However, the majority of reentry students in studies conducted by Mac 
Lean, Knoll, and Kinney (1985) and Whelan (1984) believed they had benefited from the educational program, and that they were more aware of the meaning of professionalism. Whelan also reported that the graduating students held stronger orientations toward the professional and service concepts and were less oriented to bureaucratic values.

Socialization into professional nursing is a complex process that is influenced by a variety of environments and interrelationships with many persons and groups. The two theoretical frameworks of identity development and reference groups were used as the basis of Dalme's (1983) study to examine student attitudes toward the nursing profession and their perception of the influence of peers, faculty, and staff nurses.

The findings suggested that the peer group had a constant influence which may be due to the sharing of common experiences, and the communication network between upper and lower classmates. Faculty in clinical education were viewed as having a powerful influence on the development of professional identity, particularly in the second year. These results indicated a growing sense of trust in the faculty's capability of theoretical and clinical expertise.

Staff nurses were seen as alternative role models who were valued for their competence and decision-making abilities. As the students came in contact with both 
groups, attitudes and behaviors were adapted to meet the individual's perception of the professional nurse. Students also wanted objective evaluation of their performance, and opportunities to express their opinions without fear of criticism. They desired a proper balance between theory and practice so that they felt prepared to function in clinical situations. Dalme concluded that the important influence of faculty and staff nurses in developing professional identity must be considered by nurse educators and administrators.

A copy of the instrument developed by Dalme (1979) was reviewed for content of items and scoring procedures. The scales on perceptions of faculty and staff nurses were particularly useful in identifying the areas of support that students believe to be beneficial in their preparation for the professional role. These include the encouragement for students to be creative, independent, and to participate in planning learning tasks. One item that asks respondents to rate satisfaction with nursing as a career choice was incorporated into the instrument administered to reentry students in the current study. Summary

The studies in this section have been based upon the socialization, role transition and social support theoretical frameworks and have helped to explain the complex events that occur as individuals take on a new 
role. They have addressed the factors that may influence the transition process and have introduced the dimension of satisfaction with the occupied role. The negative relationship between role conflict and role transition has been discussed, as well as the possibility that role transition would not occur during the resocialization process. The negative and positive influences of the academic environment structure were presented.

Several studies have identified the importance of the mentor or role model, resource person, and confidant in reducing role stress. The value of anticipatory socialization, and the indirect and direct benefits derived from professional support were mentioned.

Social support was conceptualized as a multidimensional variable, with professional support as a separate specialized form of social support. The role conflict tool developed by Rizzo et al (1970) and the professional concept tools constructed by Corwin (1968), Dalme (1983), and Pieta (1976) were particularly useful in formulating the model for this study of reentry students. These studies form the basis for the relationship between professional support, role conflict, and role transition in the theoretical model for this investigation. Comparison of Reentry student Groups

RN Students. Students in this group represent $16 \%$ of the National total of the 120,000 baccalaureate students 
(Baj, 1985); more than 22 thousand are enrolled in generic programs (Beeman, 1988). Their previous education was obtained in diploma or associate degree programs, and most had worked more than three years as staff nurses in acute care settings (Merritt, 1983). Their self-image as professional nurses is challenged by their new status as students (Shane, 1983).

The range in age has been reported to be between 25 and 40 years (King, 1986; Lee, 1988; and Mac Lean, Knoll \& Kinney, 1985). The majority are women who fulfill multiple roles including spouse, parent, and work. Men represent approximately $4.4 \%$ of all registered nurses (Johnston, 1987).

Many of the students in the study conducted by Maclean et al. (1985) had planned their educational goal as a two-step process, and they were seeking the advanced degree as a means for career mobility. Most continued to work in order to maintain their current position and to meet financial needs.

Swanson (1987) stated that most reentry RN students worked at least 30 hours per week and devoted approximately 20 hours to study. Grade point averages were above the 3.5 level. The majority preferred a flexible course schedule to comply with their multiple role commitments (Baj, 1985; Bardossi, 1980). 
Military Reentry students. Students in this group are military corpsmen who have had at least four years of active duty in the U. S. Navy, have received prior didactic and experiential technical training, and have worked in a health care setting at least one year. The majority are male, and many have held responsible independent positions.

Several have obtained licensure as vocational nurses (LVNS), and therefore, are eligible to receive credit by examination for some of the fundamental instruction in some baccalaureate programs. There is a high potential for perceived role conflict and identity crisis during the evaluation process which challenges their competency in theory and clinical skills.

These students are participants in a new innovative program devised by the Navy to provide career mobility for corpsmen and dental technicians who must complete their nursing education within 36 calendar months. Criteria for selection to the program include the completion of 30 transferable semester units of college credit, have a cumulative grade point average of 2.5 or higher, and be accepted by a National League of Nursing accredited baccalaureate program. A recommendation by the immediate commanding officer and an interview with a board of three officers are required. The individual must have a satisfactory service record and meet the physical 
standards for officer candidates. Final approval is given by the Commander of the Naval Medical Command.

No research was found in the current literature concerning this group of adult students. Personal interviews revealed that the majority were married and were parents to one or more children. Navy regulations stipulate that applicants be between the ages of 22 and 31 at the time of enroliment; the average age of the small sample size of eight students was 27 years. The sample consisted of six males and two females (Grendell, 1989). These individuals considered themselves to be adults. Most held the position as head of the household. A majority stated they believed their status as adults and their acquired knowledge and skills were devalued by the nursing faculty. All agreed that adjustment to the student role was stressful. Those who were parents expressed a sense of guilt for not being able to spend enough time with their families.

The Navy also requires these students to carry a fuli subject load each term throughout the year. outside work is discouraged. Although they receive their regular salary, they must assume the financial resporsibility for tuition and other financial obligations. Some have found it necessary to work part time in order to meet these expenses, and they have also experienced the pressures imposed by multiple roles. Men in this group also face 
the potential for gender role conflict as they enter the predominately female oriented nursing profession (Minnigerrode, Kayser-Jones \& Garcia, 1978).

Nursing is still not seen as a legitimate career choice for men. Most male nurses gravitate toward specialty areas such as emergency nursing, intensive care, and anesthesia where there are opportunities for using decision making skills and increased autonomy. The work is fast-paced in these areas, and there is usually less resistance to intimate contact with patients (Foreman, 1988). These findings were confirmed by the personal interviews. Everyone indicated they hoped to enter one of these specialty areas (Grendell, 1989).

Alvarez (1984) remarked that male nurses must consistently strive toward maintaining a balance between their self-identity as men and their roles and identity as nurses. Significant differences were found in the attitudes of male college students who had chosen typically masculine careers and the attitudes of male nursing students. A majority (65\%) of the non-nursing students agreed with a statement that men entered nursing because other predominantly male health care careers were unattainable, whereas $99 \%$ of male nursing students disagreed.

These findings were also supported by the interviews with Navy students. However, there was a strong 
motivation to obtain the baccalaureate degree as a means for career advancement and to gain officer status. Most intended to remain in the military during their professional career.

Summary

There are many similarities among the two groups of reentry adult students. The individuals have assumed multiple adult roles that can be impacted by the challenging student role. They have identified themselves as competent health care workers, and are comfortable in the clinical setting. Many of the reported conflicts were related to the contrasts in philosophies of the baccalaureate program and the technical orientation of the previous education and clinical environment. Many believed that information was repetitive and unnecessary.

There is also a great deal of diversity within each group and between the groups due to their multiple roles, their varied experiences, and type of previous education. The gender differences can also be contributing factors to specific role conflicts and role strain.

Chapter Summary

The literature review has considered a number of empirical studies that are related to the linkages of the model developed for this study. A basic framework of role theory has been used in selecting the studies. A concerted effort was made to include studies that were 
associated with the two role theory branches of structural functionalism and symbolic interaction. These

investigations serve as prototypes of research reported in nursing and social science literatures. The theory of social support, with its subconcept of professional support, was used to explore the influence of support as an intervening variable between role conflict and role transition.

In addition to serving as resources for validating the theoretical model constructed for this study, the reports have made valuable contributions to item construction of the intrarole conflict inventory, and in the development of the study design.

Some of the investigations were conducted in the late 1960s and 1970s. The recent changes in social values may weaken the validity of these findings. For this reason, whenever possible, related studies that were conducted at a later date were included in the discussion. A point of interest is that many of the same problems associated with multiple and focal roles and the effects of support are contemporary issues.

Personal interviews with a small group of military students indicated they had experienced similar conflicts as those reported by the returning RNs. These subjects also expressed their anxiety over the testing procedures on past education and work experience with the resultant 
threats to their self-image. Many reported frustration over repetition of information.

Due to the large number of men in the military group, a review of literature related to male nurses was done. These studies revealed the various problems related to minority groups within a social structure, and the methods that were used to alleviate stress, i.e., choosing specialty areas where there was a greater social acceptance.

Empirical evidence was presented to validate inclusion of each linkage in the model. The influence of professional support in helping to resolve role conflicts that lead to role strain, and its impact on role transition is a global theme of the proposed study model.

The increase in the number of adult students returning to the class room either for career mobility, or for career change, necessitates that research be conducted that will assist educators and administrators in identifying areas needing professional support, in designing curriculum, and planning learning experiences. Research will also help to identify areas where support measures are needed to enhance the transitional process. The goal of the advanced degree is to develop professional practitioners and stronger nursing leaders for the future. 
Chapter III

Methodology

Design

A comparative correlational design using path analytic techniques was chosen to explore the relationships between the selected variables that affect role conflict and role transition for the adult reentry student. In this recursive model, the exogenous variables, i.e., those having influence outside the present model are the background characteristics of the reentry student that include: the Number of Occupied Social Adult Roles (X1) Focal Role Occupancy (X2), Previous Education (X3), and Work Experience (X4). The endogenous variables contained within the model are: Professional Support (X5) Role Conflict (X6), and Professional Role Transition or self-identification with professional role (X7).

A unidirectional linear design, or recursive model, of path analysis was used. This model is based upon a time ordering sequence. Time ordering for this study places the exogenous variables of the reentry student characteristics in Time 1, professional support in Time 2, role conflict in Time 3 , and professional role transition 
in Time 4 (see Figure 1). A copy of each instrument is included in Appendices $G$ to $J$. The structural equations are depicted in Table 1. Samples and Procedure

Prior to data collection, the study was reviewed and approved by the committee for the Protection of Human Subjects at the University of San Diego. The description for gaining entre and the selection of the sample population is included in the following section.

Group 1. (RN reentry students). A National League of Nursing (NLN) list of public and privately supported generic baccalaureate programs that offer RN placement in the curriculum was used for the random selection of schools. One to two schools were selected from each of the 50 states, Puerto Rico, and the Virgin Islands.

A brief description of the proposed study was sent to the directors of the 65 selected schools along with a request for permission to recruit $\mathrm{RN}$ students enrolled in their programs as participants. The directors were also asked to indicate the number of RN students currently enrolled, and to provide the name of a faculty member who would accept the responsibility of contacting the students and dispersing the questionnaire packets to those who volunteered to participate (Appendix A). 
Table 1

Structural Equations for the just-identified causal model

The Number of Current Social Adult Roles

$\mathrm{X}_{1}=\mathrm{e}_{1}$

A Focal Role Occupancy.

$x_{2}=e_{2}$

Previous Education

$x_{3}=e_{3}$

Work Experience

$x_{4}=e_{4}$

Professional Support

$X_{5}=P_{51} X_{1}+P_{52} X_{2}+P_{53} X_{3}+P_{54} X_{4}+e_{5}$

Role Conflict

$X_{6}=P_{61} X_{1}+P_{62} X_{2}+P_{63} X_{3}+P_{64} X_{4}+P_{65} X_{1}+e_{6}$

Transition to Professional Role

$X_{7}=P_{71}+P_{72} X_{2}+P_{73} X_{3}+P_{74} X_{4}+P_{75} X_{5}+P_{76} X_{6}+e_{7}$

Note.

$P_{11}$ represents impact of one variable on another and will be replaced with path coefficients following statistical analysis.

$X$ equals measured variables for which data is collected.

e equals residual or error terms that are not measured but can influence the variable. 
Additional information was provided for review by three of the schools' research committees as requested. All participating programs were assured that a summary report would be sent when the study was completed. The sample population was recruited from 44 schools, or $68 \%$ of those contacted. Packets completed by students enrolled in 38 of these schools were judged to be appropriate (with minimal missing data) for inclusion in the study.

Students were enrolled in clinical nursing courses. Those who were licensed to practice as registered nurses were graduates of diploma or associate degree programs. Students occupied at least one of the roles of spouse, parent, or worker in addition to the student role. Both male and female nurses were included. A quota sampling of 120 was set to represent RN students enrolled in generic nursing programs throughout the United states.

In order to adjust for possible bias in responses from the larger schools an arbitrary maximum number of 25 packets was set for each school. $\AA$ total of 737 questionnaire packets were distributed to the various schools. There were 235 packets returned, yielding a response rate of $32 \%$ and 206 (28\%) questionnaires from the $\mathrm{RN}$ students were retained in the study.

A packet of instruments with a letter of instructions (Appendix B) was sent to the contact faculty member in each school for distribution. Each packet consisted of an 
informed consent (Appendix C) a letter to the respondent (Appendix D), the questionnaires, and a stamped addressed return envelope.

In order to create uniformity in conditions, students were asked to complete the questionnaires at their leisure at the end of a clinical day. The instructions stipulated that questionnaires were to be returned directly to the researcher within two weeks of receiving them. Coding numbers were used to indicate response rate from the various locations.

Group 2 (Military personnel). A description of the proposed study and a request to recruit the military personnel enrolled in the Medical Enlisted Commissioning Program (MECP) was sent to the commanding officer of the Navy Medical Command in Washington, D. C. Permission was granted, and a contact person was designated (Appendix E). Ninety-six persons were currently enrolled in the program during spring, 1990 when the data was collected. The total population was accessible for inclusion in the study. All enlisted U. S. Navy personnel had at least four years of active duty and at least one year of work experience in a health care setting. Some of the subjects were eligible for licensure as vocational nurses (LVN). Subjects occupied at least one of the roles of spouse, parent, or worker in addition to the student role. Both male and female corpsmen were included. To meet the Navy 
requirements, subjects must be able to complete the baccalaureate program within 36 months, attend classes year round, and graduate by age 32 .

In order to protect anonymity of the military students, the questionnaire packets, including an introductory letter (Appendix F) and consent form (Appendix C) were sent directly to the Navy headquarters. Individual postage paid packets were, then, addressed and sent by Navy personnel to the students enrolled in generic baccalaureate nursing programs in several states. The researcher was notified that all 96 packets had been mailed. There were 42 questionnaires returned ( $44 \%$ ) with 37 (39\%) satisfactory for inclusion in the study. The response rate represented students from 15 states as indicated by postal cancellation stamps.

Students were asked to complete the questionnaires at their leisure at the end of a clinical day and to return them directly to the researcher within two weeks of receiving them. Coding procedures were used for group identification.

A description of the total sample is seen in Table 2 . Members in both groups reported being involved with an average of six roles; and the role of spouse or parent was the predominant focal role. RNs had more preschool children, and worked significantly more hours ( $M=35$ vs $M=8$ ) per week. The RN group reported greater conflict in 
Table 2. Demographic Characteristics of Total Sample ( $N=243)$

\begin{tabular}{|c|c|c|c|}
\hline $\begin{array}{l}\text { Female } \\
\text { Male }\end{array}$ & $\frac{\mathrm{N}}{212}$ & 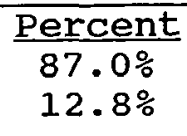 & \\
\hline $\begin{array}{l}\text { Age (Years) } \\
\text { Yrs in Relationship } \\
\text { Work (hrs/wk) } \\
\text { School (hrs/wk) } \\
\text { Study (hrs/wk) } \\
\text { Yrs Experience } \\
\text { Roles }\end{array}$ & $\begin{array}{c}\text { Range } \\
21-55 \\
1-39 \\
4-60 \\
2-56 \\
1-50 \\
1-29 \\
2-9\end{array}$ & $\begin{array}{l}\text { Mean } \\
35.56 \\
11.50 \\
30.45 \\
14.00 \\
14.50 \\
9.14 \\
5.69\end{array}$ & $\begin{array}{r}\text { S.D. } \\
7.23 \\
8.61 \\
11.34 \\
8.80 \\
8.90 \\
6.11 \\
1.78\end{array}$ \\
\hline $\begin{array}{c}\text { Number of Children } \\
\text { PreSchool } \\
\text { El.School } \\
\text { JHSchool } \\
\text { Other }\end{array}$ & $\begin{array}{l}\text { Range } \\
1-3 \\
1-5 \\
1-3 \\
1-3\end{array}$ & $\begin{array}{l}\mathrm{N} \\
55 \\
79 \\
65 \\
40\end{array}$ & $\begin{array}{c}\text { Percent } \\
23 \% \\
33 \% \\
27 \% \\
16 \%\end{array}$ \\
\hline $\begin{array}{l}\text { Education Level (Yrs) } \\
13 \\
14 \\
15 \\
16 \\
18 \\
20\end{array}$ & & $\begin{array}{r}23 \\
111 \\
86 \\
19 \\
3 \\
1\end{array}$ & $\begin{array}{r}9 \% \\
46 \% \\
35 \% \\
8 \% \\
1 \% \\
-\end{array}$ \\
\hline $\begin{array}{l}\text { Focal Role } \\
\text { Spouse } \\
\text { Parent } \\
\text { Work } \\
\text { Daughter/son } \\
\text { Student } \\
\text { Other }\end{array}$ & & $\begin{array}{r}102 \\
94 \\
19 \\
9 \\
4 \\
14\end{array}$ & $\begin{array}{r}42 \% \\
39 \% \\
8 \% \\
4 \% \\
2 \% \\
6 \%\end{array}$ \\
\hline
\end{tabular}


adjusting to the student role. RNs also indicated slightly higher conflict scores for focal role, previous education, and work experience as contributors to role conflict in the student role. The Navy students spent more hours $(M=24$ vs $M=12.4)$ in school and study. This group also reported an average of more work experience. Comparison groups in the study. Due to the relatively small sample of military students $(n=37)$, and inclusion of male subjects, a random selection was taken from the larger group of RN students to form the comparison group for testing the research hypotheses. Age and gender were used as the selection criteria. There were 22 males (59.5\%) and 15 females (40.5\%) in the military group. The age range was 23 to 34 with a mean age of 29 years.

The comparison group was comprised of all nine male RN students who were matched by age with nine of the male military students. Twenty-eight female RNs were paired by age with the remaining 13 males and 15 females included in the military group. The age range was 23 to 50 with a mean age of 30.5 years. Demographic data of the two groups is summarized in Table 3. Descriptive and ANOVA procedures were used for data analysis. Instruments

The discussion of the instruments will be structured in the order of the hypothesized path analytic model which 
Table 3. Comparison of Demographic Variables Between Military Personnel Group $(\mathrm{N}=37)$ and R.N. Group $(\mathrm{N}=37)$

\begin{tabular}{|c|c|c|c|c|c|c|}
\hline & \multicolumn{4}{|c|}{ Group I (Navy) } & \multicolumn{2}{|c|}{ Group II (R.N.) } \\
\hline $\begin{array}{l}\text { Female } \\
\text { Male }\end{array}$ & & $\begin{array}{l}N=15 \\
N=22\end{array}$ & & & $\begin{array}{l}N=28 \\
N=9\end{array}$ & \\
\hline Age & $\frac{\text { Range }}{23-34}$ & $\frac{\text { Mean }}{25.27}$ & $\frac{\%}{-}$ & $\frac{\text { Range }}{23-50}$ & $\frac{\text { Mean }}{30.50}$ & $\frac{\%}{-}$ \\
\hline $\begin{array}{l}\text { Years in } \\
\text { Relationship }\end{array}$ & $1-15$ & 7.00 & - & $1-13$ & 6.38 & - \\
\hline $\begin{array}{l}\text { Children } \\
\text { Preschool Age }\end{array}$ & $1-02$ & 1.00 & $57 \%$ & $1-03$ & 2.00 & $30 \%$ \\
\hline Elementary Age & $1-02$ & 1.04 & $49 \%$ & $1-03$ & 1.50 & $32 \%$ \\
\hline Jr/High Age & $0-01$ & - & $3 \%$ & $0-01$ & - & $3 \%$ \\
\hline School (hrs/wk) & $7-56$ & 24.00 & - & $3-26$ & 12.41 & - \\
\hline study (hrs/wk) & $3-40$ & 20.00 & - & $3-21$ & 10.65 & - \\
\hline Yrs Experience & $1-30$ & 12.00 & - & $1-30$ & 10.00 & - \\
\hline Yrs in Program & $0-03$ & 3.00 & - & $2-09$ & 3.00 & - \\
\hline $\begin{array}{c}\text { Years of Education } \\
13 \\
14 \\
15 \\
16\end{array}$ & & $\begin{array}{r}(\mathrm{N}) \\
23 \\
10 \\
0 \\
4\end{array}$ & $\begin{array}{l}\frac{\%}{62 \%} \\
27 \% \\
- \\
11 \%\end{array}$ & & $\begin{array}{c}(\mathrm{N}) \\
0 \\
23 \\
13 \\
1\end{array}$ & $\begin{array}{l}\frac{\%}{-} \\
62 \% \\
35 \% \\
3 \%\end{array}$ \\
\hline $\begin{array}{l}\text { Focal Role } \\
\text { Spouse } \\
\text { Parent } \\
\text { Work } \\
\text { Son/Daughter } \\
\text { Student } \\
\text { Other }\end{array}$ & & $\begin{array}{r}1 \\
20 \\
1 \\
4 \\
5 \\
0\end{array}$ & $\begin{array}{r}30 \% \\
54 \% \\
3 \% \\
11 \% \\
14 \% \\
-\end{array}$ & & $\begin{array}{r}18 \\
12 \\
3 \\
3 \\
0 \\
1\end{array}$ & $\begin{array}{l}49 \% \\
32 \% \\
8 \% \\
8 \% \\
- \\
3 \%\end{array}$ \\
\hline
\end{tabular}


is depicted in Figure 1 (See page 16). Five instruments were used to form the questionnaire. A demographic profile form (Appendix G) was developed to collect information on the exogenous variables namely: number of occupied roles, focal role occupancy, type of previous education, and years of work experience. Subjects were asked to record descriptive data on age, length of marital status (or significant partner relationship) number of children, amount of hours devoted to work, attendance at school, and study time per week, as well as the length of time in the academic program and projected graduation date.

A scale of 1 to 5 was used to designate the perceived degree of conflict in adjusting to the student role and the influence of multiple roles, focal role commitment, previous education and work experience on the conflict. A final item (located at the end of the questionnaire) was included to identify satisfaction or dissatisfaction with nursing. A range from 1 to 4 was used, with 4 indicating greatest satisfaction.

Five open-ended statements regarding conflicts due to the student role were provided to allow subjects to expand their comments. This information will be useful for future study.

Professional support. Professional support was measured by the Goldberger Professional Support Scale 
(GPPS) developed in 1986. The tool is based on the premise that professional, or formal support, is fundamentally different from social, or informal support. The professional person is defined as one who has a special educational background and can provide counsel or assistance with specific problems. (See Appendix I).

The self-administered scale consists of 65 short answer items and is anchored by a 5-point Likert summated rating scale. Responses range from never (1) to almost always (5). Some negative items are included to avoid response bias. These are reverse scored during analysis resulting in a possible range of total scores between 65 to 325. An overall high score indicates a greater perception of professional support.

The instrument was pilot tested with a convenience sample of volunteer subjects who had received the assistance of a professional person within the past four months. The sample consisted of 52 females and 8 males with an age range from 20 to 74 (mean age, 33.6 years). Thirty-five of the subjects structured their responses based on their interaction with a nurse; 12 based their responses on contact with a physician; 13 selected other professionals. Internal reliability consistency iavels for the three dimensions of professional communication skills, direct, and indirect problem solving skills ranged from .88 to .94 . Intercorrelations of these dimensions 
ranged from .80 to .99 suggesting a unidimensional concept of professional support.

The instrument has also been used with hypertensive clients who were asked to respond to the items in light of their contact with a nurse who managed their hypertensive care. A standardized alpha coefficient of .97 was obtained using 59 of the 65 items.

In the current study, reentry students were asked to respond to the items in relationship to a professional person who had provided them with professional support since their return to school. Fifty-seven items were retained resulting in a Cronbach alpha of .97.

Role conflict. Role conflict was measured by the Grendell Role Conflict Inventory (GRCI) (Grendell, 1989). Fifty-three items are randomly dispersed in five dimensions related to major life roles as parent, spouse, work, social, and personal/self roles. Items were constructed for the subscales of (1) intrarole conflict (2) role expectations, and (3) role motivation to represent potential intrarole conflict in each of the five role sets. Subjects were asked to respond to each item in relation to the impact of the student role on their other activities. A 4-point Likert scale is used with a range from strongly disagree (1) to strongly agree (4). The total degree of conflict is represented by the summation of scores that has a possible range of 53 to 212 with a 
higher score indicating a greater degree of role conflict. Three negative items were included to avoid response set. These items are reverse scored in the final analysis. In the current study; one additional item (included on the demographic sheet) directed the student to rate the degree of conflict experienced due to the addition of the student role on a scale from (1) no conflict to (5) high conflict. The instrument was developed using the role theory framework and was submitted to a panel of five judges for validation of content validity. Items receiving scores equal to or greater than 75 percent of agreement were retained. Pilot testing was conducted with a recruited sample of 27 reentry students. The results indicated high inter-item correlation with standardized alpha levels above .70 for all scales, therefore, suggesting it is a unidimensional measure (Nunnally, 1978). The final standardized Cronbach alpha level was .93.

The findings also revealed a moderate correlation between the instrument and a parallel measure of role conflict developed by Kopelman, Greenhaus, and Connelly (1983). The correlations were .61 between the total Grendell Role Conflict inventory score and the work score of the Koppelman tool; .56 with the family score; and .46 with the interrole score of the Koppelman tool. The instrument was retested for credibility of subscales in the current study, and was determined to be a 
unidimensional instrument containing 40 items with a standardized Cronbach alpha of .97.

Professional role transition. Professional role transition, or self-identity with the professional role, was measured by the instrument developed by Pieta (1976). The instrument consists of the three role conceptions of loyalty to bureaucratic or organizational policies, to professional ideals, and to humanitarian service. An individual can value all three role conceptions in varying degrees at any one time. (See Appendix J)

The three role conceptions, or set of expectations, of the nursing role are placed within thirty-four hypothetical hospital situations which are randomly dispersed throughout the instrument. The Bureaucratic Role Conception Scale contains 12 items, the Professional Role Conception Scale, 10 items, and the service Role Conception scale, 12 items. Items are anchored by a five-point scale ranging from strongly agree (5) to strongly disagree (1). Response A to each item is concerned with the ideal, or normative action; response $B$ is the actual practice, or categorical, action as perceived by the respondent.

Normative, categorical, and discrepancy scores are computed for each subscale. There is a possible range of scores from 12 to 60 for Bureaucratic and Service Role Conception subscales and 10 to 50 for the Professional 
Role Conception subscale. The role discrepancy score is the difference between the ideal and actual subscale scores. The arithmetic mean of each subscale is obtained by dividing the total score by the number of items resulting in a mean score between one and five. The discrepancy mean score is derived by subtracting the means across the two scales. For each situation, the numerical mean difference $\left(M_{D}\right)$ can range from +4 to -4 .

A negative score suggests that the actual practice situation exceeds the individual's expectation for this situation. A positive discrepancy score suggests that the actual practice does not meet the individual's expectations. A greater discrepancy score may also be related to a higher degree of role conflict.

Content validity testing of the instrument was achieved through the use of a panel of educators and nursing administrators. The Cronbach coefficient alpha formula was used to test internal consistency yielding .84 for the Bureaucratic Role Conception scale, .63 for the Professional Role Conception scale, and .58 for the Service Role Conception scale. Predictive validity was tested by the known group method, with faculty having the highest scores on the professional subscale; nurse administrators the highest scores on the bureaucratic scale; and nurses with religious commitment, the highest scores on the service scale. The test/retest reliability 
yielded correlation coefficients of .83 for the Bureaucratic scale, .86 for the Professional scale, .81 for the Service scale, and .92 for the total instrument. Forrester (1983) used the Bureaucratic and Professional sub-scales with 208 female baccalaureate nurses to investigate the relationship between sex-role identity and perceptions of nurse role discrepancy. She reported Chronbach alpha reliability estimates of . 67 for Professional ideal and .69 for actual role conception subscales, and .67 and .51 for the respective Bureaucratic Role Conception subscales.

Burrows (1982) reported Chronbach alphas of .55 for service, .74 for bureaucratic, and .66 for professional ideal role conception scales when the instrument was administered to 126 staff nurses to examine normative (ideal) role conceptions and integrative resolution of nursing care dilemmas.

\section{Data Analysis Techniques}

The Statistical Package for the Social Sciences (SPSS-X) was used for computer analysis. Frequencies, percentages, means, standard deviations, and scattergrams were performed to determine normal distribution and linearity ố data for all variables. All variables were subjected to analysis by Pearson product-moment correlations, residual scatterplots of endogenous variables and error terms (Tabachnick \& Fidell, 1983). 
Path analysis was used to define and explain the model. The salient beta weight of $\geq .10$ or a probability level of at least .05 were accepted as criteria for retaining a variable path (Land, 1969). $\mathrm{R}^{2}$ or the adjusted $R^{2}$, when significantly different, was used to determine the proportion of variance of criterion variable in each equation explained by predictor variables (Tabachnick \& Fidell, 1986). Given a sample size of 120 subjects, a power of .87 is suggested for this study based on an $\mathrm{L}$ (effect size estimate) of 16.84, a $\mathrm{u}$ (independent variable) of 6 , and a probability level of .05 (Cohen, 1977 ).

A ratio of 20 subjects for each variable was suggested by Tabachnick and Fidell (1983) for regression analysis. A minimal requirement of at least four to five subjects to each variable was also suggested. Sample size is adequate for the small sample comparisons as well as for the total group of subjects. Assumptions Underlying Statistical Procedure

Path analysis is an appropriate method to aid in clarification of causal influences of one variable on another and to assist in the development of theory (Asher, 1983; Munro, Visitainer, \& Page, 1986; Polit \& Hunger, 1989; Volicer, 1984; Waltz \& Bausell, 1981). The major underlying assumptions in the application of path analysis according to these authors are: 
1. The causal flow is unidirectional.

2. Variables are measured at the interval level.

3. Relationships between variables within the model are considered to be linear, additive, and causal.

4. Residuals are not correlated with other residuals or variables within the model.

5. More than one regression analysis may be needed with dependent variable regressed on all variables it depends upon.

6. Exogenous variables are not influenced by endogenous variables within the model.

7. All relevant variables are included in the model.

8. Homoscedasticity is evident by a constant variance in the error term for different values of $\mathrm{X}$.

Bivariate correlations and residual analysis. Pearson bivariate correlation coefficients were run on all variables included in the model. Due to the fact that focal role (X2) did not correlate with the outcome variables within this study, the current work role was substituted. The matrix is shown in Table 4. No evidence of multicollinearity was present since none of the bivariate correlations were $\geq .7$. 
Table 4. Correlation Matrix of All Variables

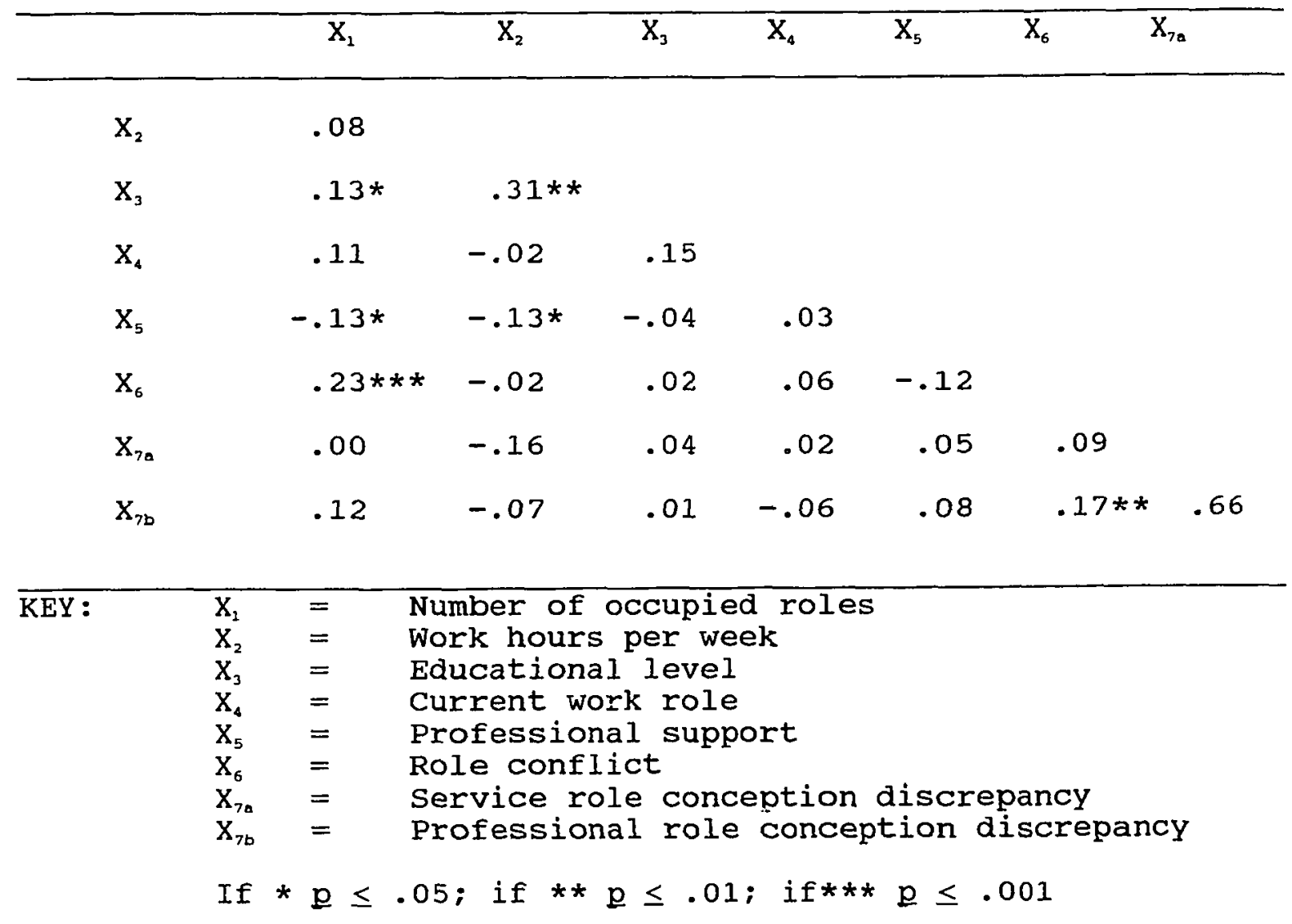


After regressions were run, the assumptions underlying residual analysis were checked by the following assessments as suggested by Verran and Ferketich (1984). The means of the residuals were equal to zero, and the histogram of residuals indicated normal distribution. There was a random scattering and even distribution of points about the line from the lower left to the upper right of the scatterplot, thus indicating constant variance of the error terms and linearity of the measured phenomena. 


\section{Chapter IV. \\ Results}

Verification of Measurement Properties

The initial psychometric properties of the instruments (Professional support, Role conflict Inventory, and the Role conception Scale) were examined. The results are summarized in Table 5 .

The Professional Support scale had strong reliability with a standardized alpha of .97 with 57 (88\%) items retained. Similar findings were reported in the previous study with hypertensive subjects retaining 59 (91\%) items with standardized alpha of .97 (Goldberger, 1990). Prior research has also established it to be a unidimensional instrument.

The three original dimensions of the Role Conflict Inventory (Grendell, 1989) were rearranged into a unidimensional scale since the reliability levels were above the recommended .70 alpha level (Nunnaly, 1978). This was further supported through factor analysis. Although eleven factors emerged that identified $63 \%$ of the variance, there was a sharp scree slope between the first factor and the following factors. Upon examining the communalities of the final three factor matrix, factor one 
Table 5. Initial Reliabilities of Instruments

\begin{tabular}{|c|c|c|c|}
\hline $\begin{array}{l}\text { Scale } \\
\text { Subscale }\end{array}$ & $\begin{array}{l}\text { Mean } \\
\text { Inter-item } \\
\text { Correlation }\end{array}$ & $\begin{array}{l}\# \text { of Items } \\
\geq .35 \text { for } \\
\text { Corrected } \\
\text { Item-Total } \\
\text { Correlation } \\
\quad(\%)\end{array}$ & $\begin{array}{c}\text { Alpha } \\
\text { Coefficient } \\
\text { Standardized }\end{array}$ \\
\hline $\begin{array}{l}\text { Goldberger Prof. } \\
\text { Support Scale }\end{array}$ & .38 & $57(99 \%)$ & .97 \\
\hline $\begin{array}{l}\text { Grendell Role } \\
\text { Conflict Scale }\end{array}$ & .25 & $40(75 \%)$ & .92 \\
\hline $\begin{array}{l}\text { Pieta Role } \\
\text { Conception Scales } \\
\text { Ideal } \\
\quad \text { Service }\end{array}$ & & & \\
\hline $\begin{array}{l}\text { Role Conception } \\
\text { Prof. Role }\end{array}$ & .27 & $5(42 \%)$ & .65 \\
\hline $\begin{array}{l}\text { Conception } \\
\text { Bur. Role }\end{array}$ & .31 & $6(60 \%)$ & .73 \\
\hline $\begin{array}{l}\text { Conception } \\
\text { Actual } \\
\text { Service }\end{array}$ & .28 & $6(50 \%)$ & .63 \\
\hline $\begin{array}{c}\text { Role Conception } \\
\text { Prof. Role }\end{array}$ & .29 & $5(42 \%)$ & .67 \\
\hline $\begin{array}{l}\text { Conception } \\
\text { Bur. Role } \\
\text { Conception }\end{array}$ & .32 & $6(50 \%)$ & .73 \\
\hline
\end{tabular}


had large factor loadings (exceeding 3.0) on all items. only five items evidenced factorial complexity with moderate loadings on two factors. Based on these findings, the inventory was judged to be a unidimensional scale (Hinkle, Wiersma, Jurs, 1979). Reliability testing of the total scale for this study resulted in a standardized alpha of .92 with 40 (75\%) of the 53 items meeting the critical level of $\geq .35$ for the corrected item-total correlation. Initially, the three Role Conception (Pieta, 1976) subscales (bureaucratic, service, and professional) were subjected to reliability testing. Because the discrepancy score of each subscale is dependent upon the difference between the normative (ideal) and actual practice (categorical) scores, pair wise deletion of items was an essential part of reliability testing. This resulted in retaining six of the ten items (60\%) for the professional role conception scale and five of the twelve items (42\%) in the service role conception scale. Six of the twelve bureaucratic normative items ( $50 \%$ ) met the recommended levels for reliability; however, none of the matching items in the categorical role conception scale reached the significance level. Therefore this subscale was deleted from further analysis. 
Testing of the Model

All of the variables of the model were entered into the regression analysis beginning with professional support, the earliest dependent endogenous variable. Regression proceeded to the next dependent variable, role conflict. Separate regressions were performed with the two subscales of service role conception discrepancy and professional role conception discrepancy (see Figure 2).

Path coefficients, or standardized beta weights, and their significance levels were examined along with the amount of variance $\left(R^{2}\right.$ and adjusted $R^{2}$ ) accounted for by each of the independent variables (Munro, visintainer, \& Page, 1986). Due to the large sample size the $\mathrm{R}^{2}$ was used to designate the amount of variance. In order to retain a variable path, levels of predictive ability were set at a beta weight of $\geq .10$ and a significance level of .05 (Munro \& Sexton, 1984; Pedhazur, 1984). The standardized regression coefficients ( $\underline{b} \geq .10$ ) relating the endogenous variables to the predictor variables are presented in Table 6 .

Three percent of the variance in professional support $(F=3.58, \underline{p} \leq .03)$ was accounted for with the major influence due to the salient inverse effect derived from the number of occupied roles $(\underline{b}=-.122, F=3.21$, $\underline{p} \leq .07)$ and current work hours $(\underline{b}=-.125, \underline{p} \leq .07)$. In the third time ordering, $4 \%$ of the variance $(F=3.08$, 


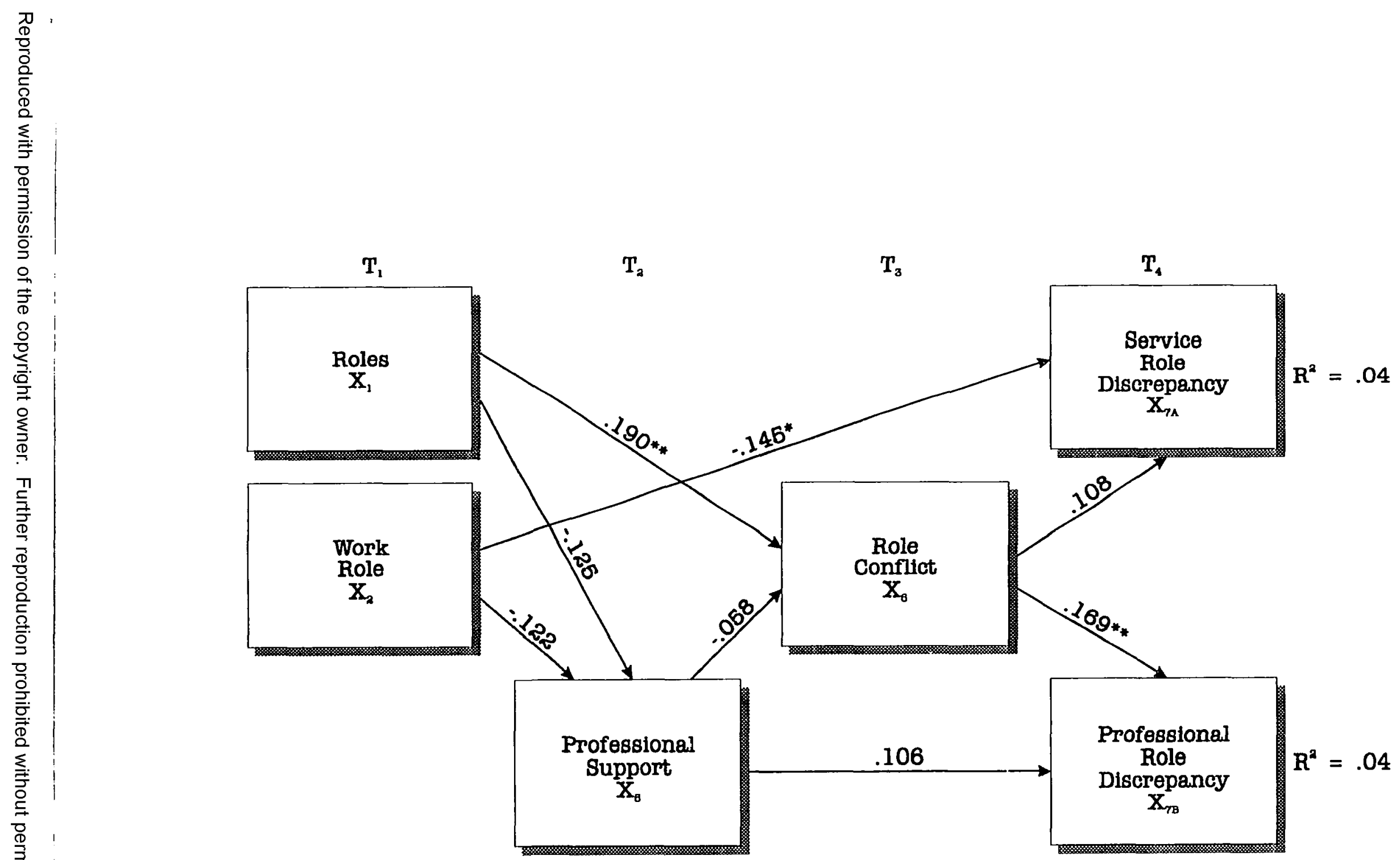

Note Path Significance: ${ }^{*} \mathrm{p} \leq .05,{ }^{* *} \mathrm{p} \leq .01$

Standardized beta weights are shown on the paths between variables.

Figure 2. Simplified Path of Model Relating Service Role Conception Discrepancy and Professional Role Conception Discrepancy to Predictor Variables (path coefficient $\geq .10$ ). 
Table 6. Standardized Regression Coefficients ( $\underline{b} \geq .10$ ) Relating Remaining Endogenous Variables to the Predictor Variables in Simplied Model

\begin{tabular}{|c|c|c|c|c|}
\hline \multirow[b]{2}{*}{$\begin{array}{l}\text { Independent } \\
\text { Variables }\end{array}$} & \multicolumn{4}{|c|}{ Dependent variables } \\
\hline & $\begin{array}{l}\text { Prof. } \\
\text { Support }\end{array}$ & $\begin{array}{c}\text { Role } \\
\text { Conflict }\end{array}$ & $\begin{array}{l}\text { Service Role } \\
\text { Discrepancy }\end{array}$ & $\begin{array}{l}\text { Prof. Role } \\
\text { Discrepancy }\end{array}$ \\
\hline Roles & -.13 & $.190 * *$ & .108 & \\
\hline Work & -.12 & & $-.145 *$ & \\
\hline Prof. Support & & & & .106 \\
\hline Role Conflict & & & & $.169 * *$ \\
\hline
\end{tabular}

$* \underline{p} \leq .05 \quad * * \underline{p} \leq .01$ 
$\underline{p} \leq .03$ ) in role conflict was accounted for by the direct effect due to the number of occupied roles $(\underline{b}=.190$, p $\leq .001)$.

Service role conception discrepancy was regressed on antecedent variables of role conflict, professional support, current work role, and number of occupied roles. Four percent of the variance in service role conception discrepancy $(F=2.03, \underline{p} \leq .07)$ was accounted for by the antecedent variables with the greatest influence brought by the direct inverse effect of the work role ( $\underline{b}=-.145$, $\underline{p} \leq .05)$.

Professional conception discrepancy was regressed on antecedent variables of role conflict, professional support, current work role, and multiple roles. Four percent of the variance in the discrepancy $(F=2.45$, $\underline{p} \leq .05)$ was accounted for by the antecedent variables with the major direct influence derived from role conflict $(\underline{b}=.169, \underline{p} \leq .01)$. Professional support had a salient $(\underline{b}=.10, \underline{p} \leq .10)$ direct positive effect on professional role discrepancy.

Roles, work role, professional support, and role conflict were retained in the model due to the actual and salient effects. Although there were small predictive correlations between education and years of experience variables with role conflict, these did not hold up during path analysis and were not retained. Since professional 
support was a major interest for this study, it was retained because of its direct salient predictive effect on professional role discrepancy $(\underline{b}=.10, \underline{p} \leq .10)$, and indirect effect via role conflict, and meaningfulness to the model. Summary of mean scores is located in Table 7. Testing the Hypotheses

A significance level of .05 was set for testing the hypotheses. There were four direct complex hypotheses. None of the hypotheses was supported as stated. Hypothesis 1 stating that the number of current occupied roles, focal role occupancy, educational level, and work experience have a direct positive effect on professional support was not supported. Salient effects were in the inverse direction ( $\underline{b}=-.122, \underline{p} \leq .07)$ between the number of occupied roles, work role, and professional support.

Hypothesis 2 was partially supported. There was a significant positive effect $(\underline{b}=.190, \underline{p} \leq .001)$ between the number of occupied roles and role conflict. There were no significant direct effects due to focal role occupancy, education level, or years of experience. Hypothesis 3 was partially supported. The inverse effect brought by professional support on role conflict did not reach a significance level. A salient level $(\underline{b}=-.058, \underline{p} \leq .03)$ was met. 
Table 7. Comparison of Mean Scores for Model Variables Between Military Personnel Group $(\mathrm{N}=37)$ and RN Group ( $N=37)$

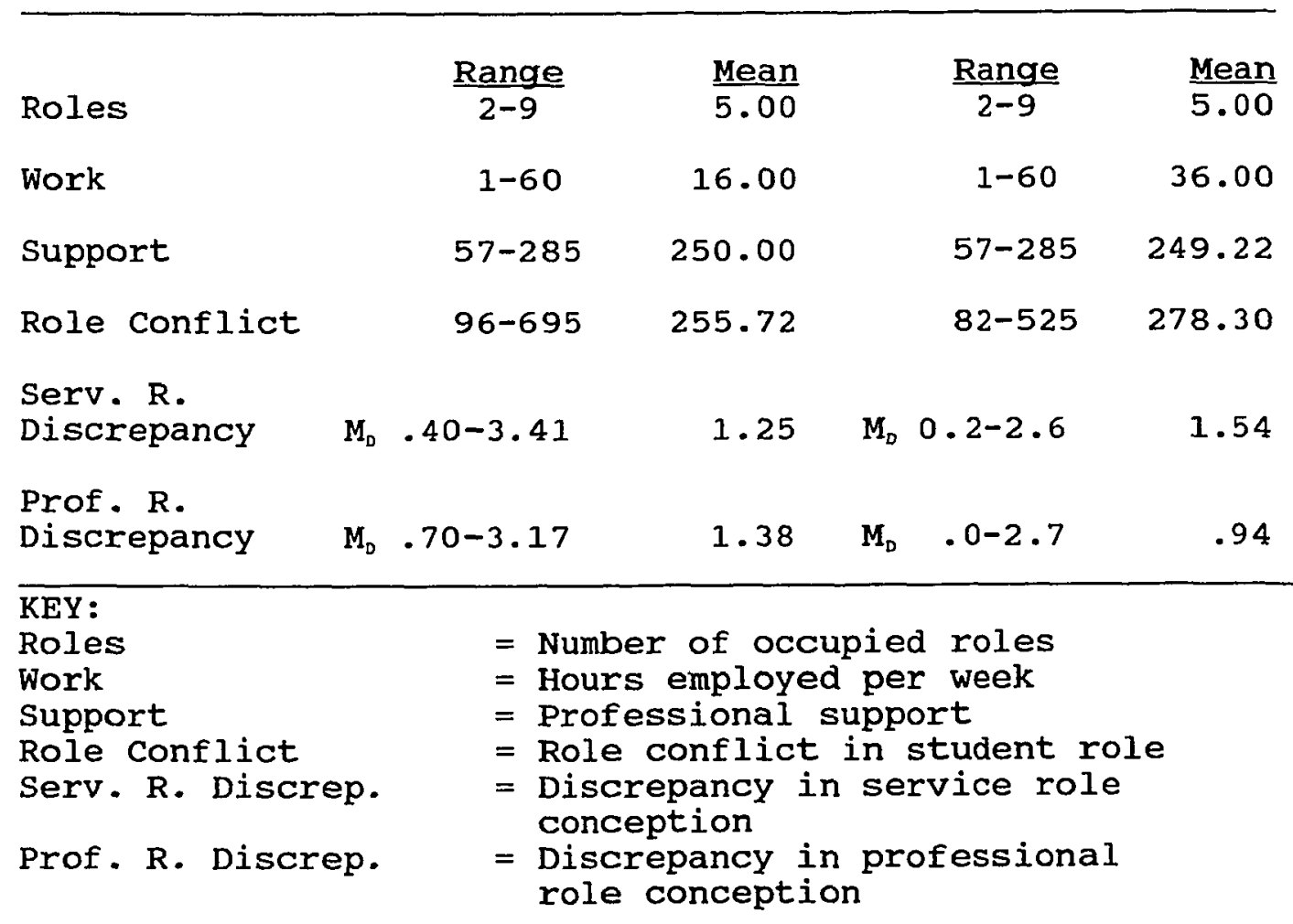


Hypothesis 4 was not supported. Effects of role conflict on professional and service role conceptions were in the opposite direction than predicted. There was a salient positive effect ( $\underline{b}=.10, \underline{p} \leq .09)$ of role conflict on service role conception discrepancy, and a direct significant positive effect $(\underline{b}=.169, \underline{p} \leq .01)$ on professional role conception discrepancy.

The theoretical model had two indirect complex hypotheses. Hypothesis 5 was not supported. The salient inverse effects of multiple role occupancy and the work role on professional support, and the positive effect of role conflict on service and professional role conception discrepancies were opposite to the predicted directions. The effect of professional support on role conflict did not meet significance levels.

\section{Explanation of Variance}

Table 8 depicts the decomposition of variance for the outcome variables. Bivariate correlation coefficients and standardized beta weights (path coefficients) for direct effects are shown in columns $A$ and $B$ respectively. The indirect effects, or sum of the multiplicatives of the beta weights in the involved pathways, are in column $c$. Total effects which are the sum of direct and indirect effects are located in column D. Noncausal and spurious effects which result from subtracting total effects from the total covariance are shown in Column $\mathrm{E}$. 
Table 8. Decomposition Table of Effects of Variables

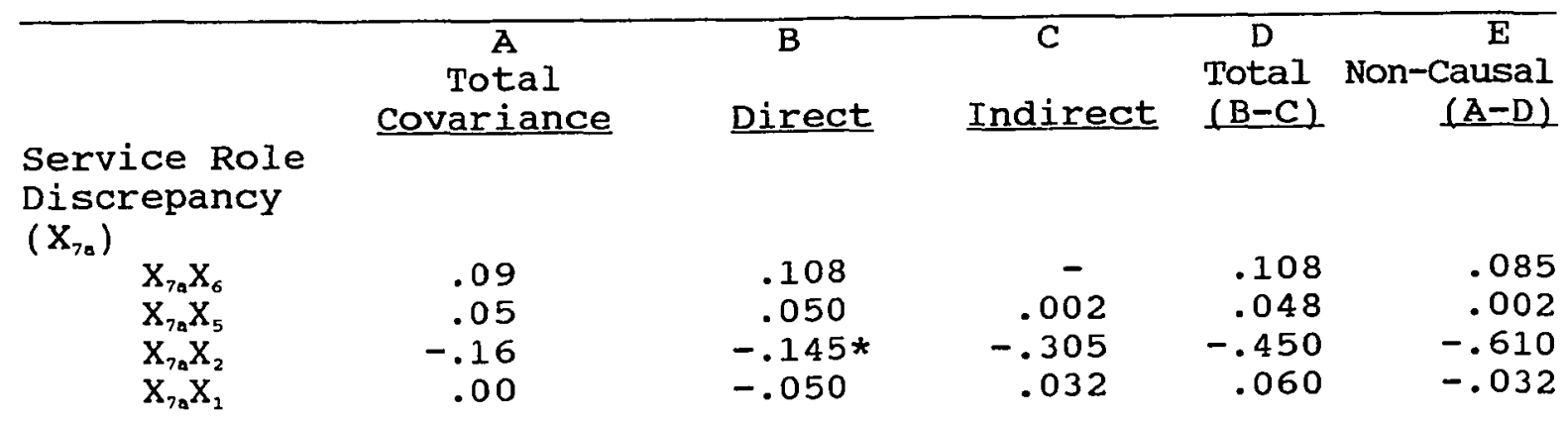

Professional

Role

Discrepancy

$\left(\mathrm{X}_{7 \mathrm{~b}}\right)$

$\mathrm{X}_{7 b} \mathrm{X}_{6}$
$\mathrm{X}_{7 \mathrm{~b}} \mathrm{X}_{5}$
$\mathrm{X}_{7 \mathrm{~b}} \mathrm{X}_{2}$

.169

.077

$-.070$

$\mathrm{X}_{7 \mathrm{~b}} \mathrm{X}_{1}$

.117
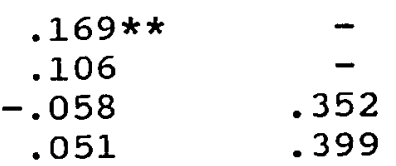

$\begin{array}{ll}.169 * * & -.137 \\ .106 & -.244 \\ -.450 & -.520 \\ -. .348 & -.170\end{array}$

Role

Conflict $\left(x_{6}\right)$

$\begin{array}{lr}\mathrm{X}_{6} \mathrm{X}_{5} & -.123 \\ \mathrm{X}_{6} \mathrm{X}_{2} & -.021 \\ \mathrm{X}_{6} \mathrm{X}_{1} & .232\end{array}$

$$
\begin{array}{r}
-.058 \\
-.043 \\
.190 *
\end{array}
$$$$
\begin{array}{r}
-.096 \\
-.180
\end{array}
$$

\section{$-.154$}

$-.277$

$.190 *$ *

$-$

$-.217$

.047

Professional

Support $\left(X_{5}\right)$

$\begin{array}{lrrrrr}\mathrm{X}_{5} \mathrm{X}_{2} & .079 & -.122 & - & -.122 & .046 \\ \mathrm{X}_{5} \mathrm{X}_{1} & -.127 & -.125 & - & -.125 & .252\end{array}$

KEY: $\quad \mathrm{X}_{1}=$ Number of Occupied Roles

$\mathrm{X}_{2}=$ Work Hours Per Week

$\mathrm{X}_{5}=$ Professional Support

$x_{6}=$ Role Conflict

$\mathrm{X}_{7 \mathrm{a}}=$ Service Role Conception Discrepancy

$\mathrm{X}_{7 b}=$ Professional Role Conception Discrepancy 
In summary, direct and indirect effects of the exogenous variables (number of occupied roles and work role) and influence of professional support on role conflict and the subsequent transition to professional role (service role conception discrepancy and professional role conception discrepancy) were examined through path analysis that resulted in the development of a simplified model composed of five variables. Small percentages of variance of the outcome variables were explained. The number of occupied roles and role conflict had the strongest total effect upon professional and service role discrepancies. The work role had the strongest direct and total inverse effect on service role discrepancy.

Hypothesis 6 was partially supported. Transition to the professional role was indirectly influenced by professional support via role conflict at a salient level. Analysis of Group Differences

The second purpose of the study was to compare the two groups of subjects when the model was applied. Prior to testing the causal model through regression procedures, analysis of variance (ANOVA) procedures were used to determine homogeneity of the two small comparison groups of 37 military personnel and 37 RNs randomly selected from the total group. Age and sex were used as the selection criteria for placement of subjects in the two groups. 
A 2 X 2 ANOVA factorial design was used to compare main and interaction effects of group and sex on the model variables. Variance in work experience $(F=7.35$, $\underline{p} \leq .01$ ) and variance in the professional role discrepancy scale $(F=4.106, \underline{p} \leq .04)$ were attributed to interaction effects. There was also a trend toward significance in the variance in role conflict due to interaction effects. The sources of variance in educational level ( $F=25.80$, $\underline{p} \leq .00)$ and current work role $(F=15.36, \underline{p} \leq .00)$ were due to main effects. The means of the RN group were higher for both variables. No other significant differences were noted. A summary of findings is depicted in Table 9 .

Following this procedure, the one-way ANOVA was done. No significant mean differences were identified in the number of occupied roles, years of experience, perceived professional support, degree of role conflict, service role or professional role conception discrepancies among the two groups.

significant differences in the years of education $(F=19.98, \underline{p} \leq .00)$ and current work hours $(F=13.41$, $\underline{p} \leq .00)$ were noted with higher group means for RNs. A summary of findings is depicted in Table 10. The Navy group mean $(M=7.6, S D 3.33)$ for work experience was greater than the RN group $(M=6.89$, SD 4.96$)$, but did not reach a level of significance. Post-hoc comparisons of 
Table 9. Two-way Analysis of Variance Between Military Personnel Group ( $N=37$ ) and R.N. Group ( $N=37$ ) Summary of Significant Findings by Group and Sex

\begin{tabular}{lrrrrrr}
\hline \multicolumn{7}{c}{ Years of Education } \\
Source of Variance & \multicolumn{2}{c}{ SS } & df & \multicolumn{1}{c}{ MS } & \multicolumn{1}{c}{ F } & p \\
\hline \multirow{2}{*}{ Main Effects } & 14.463 & 2 & 7.231 & 25.804 & .00 \\
Sam & 13.308 & 1 & 13.308 & 47.488 & .00 \\
$\quad$ Sex & .095 & 1 & .095 & .340 & .56 \\
2-Way Interactions & .008 & 1 & .008 & .030 & .86 \\
Sam Sex & .008 & 1 & .008 & .030 & .86 \\
Explained & 14.471 & 3 & 4.824 & 17.212 & .00 \\
Residual & 13.452 & 48 & .280 & & \\
Total & 27.923 & 51 & .548 & & \\
\hline
\end{tabular}

Work Hours Per Week

\begin{tabular}{lrrrrr}
\hline Source of Variance & \multicolumn{1}{c}{ SS } & df & MS & F & p \\
Main Effects & & & & & \\
Sam & 2744.340 & 2 & 1372.170 & 15.360 & .00 \\
Sex & 2526.180 & 1 & 2526.180 & 28.277 & .00 \\
2-Way Interactions & 18.335 & 1 & 18.335 & .205 & .65 \\
Sam Sex & 33.003 & 1 & 33.003 & .369 & .55 \\
Explained & 33.003 & 1. & 33.003 & .369 & .55 \\
Residual & 2777.342 & 3 & 925.781 & 10.363 & .00 \\
Total & 4288.100 & 48 & 89.335 & & \\
& 7065.442 & 51 & 138.538 & &
\end{tabular}

\begin{tabular}{|c|c|c|c|c|c|}
\hline \multicolumn{6}{|c|}{ Years of Work Experience } \\
\hline Source of Variance & SS & df & MS & $\mathrm{F}$ & $D$ \\
\hline $\begin{array}{l}\text { Main Effects } \\
\text { Sam } \\
\text { Sex } \\
\text { 2-Way Interactions } \\
\quad \text { Sam Sex } \\
\text { Explained } \\
\text { Residual } \\
\text { Total }\end{array}$ & $\begin{array}{r}77.706 \\
9.522 \\
43.513 \\
145.972 \\
145.972 \\
223.678 \\
952.841 \\
1176.519\end{array}$ & $\begin{array}{r}2 \\
1 \\
1 \\
1 \\
1 \\
3 \\
48\end{array}$ & $\begin{array}{r}38.853 \\
9.522 \\
43.513 \\
145.972 \\
145.972 \\
74.559 \\
19.851\end{array}$ & $\begin{array}{r}1.957 \\
.480 \\
2.192 \\
7.353 \\
7.353 \\
3.756\end{array}$ & $\begin{array}{l}.15 \\
.49 \\
.14 \\
.00 \\
.00 \\
.02\end{array}$ \\
\hline \multicolumn{6}{|c|}{ Professional Role Discrepancy } \\
\hline Source of Variance & SS & दf & MS & $F$ & $\underline{p}$ \\
\hline $\begin{array}{l}\text { Mair Effects } \\
\text { Sam } \\
\text { Sex } \\
\text { 2-Way Interactions } \\
\text { Sam Sex } \\
\text { Explained } \\
\text { Residual } \\
\text { Total }\end{array}$ & $\begin{array}{r}12.11 \\
2.76 \\
11.89 \\
76.01 \\
76.01 \\
88.11 \\
1295.94 \\
1384.05\end{array}$ & $\begin{array}{r}2 \\
1 \\
1 \\
1 \\
1 \\
3 \\
70 \\
73\end{array}$ & $\begin{array}{r}6.05 \\
2.76 \\
11.89 \\
76.01 \\
76.01 \\
29.37 \\
18.51 \\
18.96\end{array}$ & $\begin{array}{r}.327 \\
.149 \\
.642 \\
4.106 \\
4.106 \\
1.586\end{array}$ & $\begin{array}{l}.72 \\
.70 \\
.43 \\
.05 \\
.05 \\
.20\end{array}$ \\
\hline
\end{tabular}


Table 10

Mean and Standard Deviation Differences in Model Variables by Sex and Group (RN, Military) - One Way Ana1ysis of Variance

\begin{tabular}{|c|c|c|c|}
\hline Variables & $\begin{array}{c}\mathrm{RN} \\
(\mathrm{N}=37)\end{array}$ & $\begin{array}{l}\text { Military } \\
(N=37)\end{array}$ & F Ratio \\
\hline $\begin{array}{l}\text { Years of } \\
\text { Education }\end{array}$ & $\begin{array}{c}M=14.41 \\
(\mathrm{SD} \quad .55)\end{array}$ & $\begin{array}{l}M=13.59 \\
(\mathrm{SD} \quad .96)\end{array}$ & $19.98 * *$ \\
\hline Work & $\begin{array}{c}M=32.00 \\
(S D 9.55)\end{array}$ & $\begin{array}{c}M=16.31 \\
(\mathrm{SD} 8.74)\end{array}$ & $31.41 \%$ \\
\hline
\end{tabular}


variances using Cochrans $C$ and Bartlett's-Box tests to examine the homogeneity of variances among the two samples identified no other significant group differences.

The groups were further divided by sex into four smaller samples, and a second one-way ANOVA was run. A summary of the significant mean differences is located in Table 11. Similar findings were noted for significant mean differences due to years of education $(F=6.8, \underline{p} \leq$ $.00)$, and in the number of work hours for both male and female RN student groups $(F=10.36, p \leq .00)$. Both male and female RNs had more years of education than either of the Navy groups.

Significant mean differences were noted in work hours between group 2 ( $R N$ female, $M=32, S D 9.07$ ) and group 1 (Navy females, $M=14, S D 6.7$ ) and group 3 (Navy males, $\mathrm{M}=18$, SD 9.8); and between group 4 ( $\mathrm{RN}$ males, $\mathrm{M}=32$, SD 11.49) and group 1.

There were significant differences $(F=5.11$, $\underline{p} \leq .00)$ in the number of years experience between groups 1 and 3 with groups 2 and 4. Male RNs (group 4) had the most experience $(M=9.67, \mathrm{SD} 7.7)$ and Navy females (group 1) were second ( $M=8.9, \mathrm{SD} 2.76)$. Navy males (group 3) ranked third ( $M=6.86, S D 3.48)$, and $R N$ females (group 2) had the least experience $(M=4.93$, SD 3.09). No other significant differences were determined by Student-NewmanKeuls (SNK) ranges among the four groups. The SNK is 
Table 11

Mean and Standard Deviation Differences in Model Variables by Sex and Group (RN, Military)

\begin{tabular}{|c|c|c|c|c|c|}
\hline \multirow[t]{2}{*}{ Variables } & \multicolumn{2}{|c|}{ RN } & \multicolumn{2}{|c|}{ Military } & \multirow[t]{2}{*}{ F Ratio } \\
\hline & $\begin{array}{l}\text { Women } \\
(N=28)\end{array}$ & $\begin{array}{c}\text { Men } \\
(N=9)\end{array}$ & $\begin{array}{l}\text { Women } \\
(N=15)\end{array}$ & $\begin{array}{c}\text { Men } \\
(N=22)\end{array}$ & \\
\hline $\begin{array}{l}\text { Years of } \\
\text { Education }\end{array}$ & $\begin{array}{l}M=14.39 \\
(\mathrm{SD} \quad .57)\end{array}$ & $\begin{array}{l}M=14.44 \\
(S D \quad .53)\end{array}$ & $\begin{array}{c}M=13.73 \\
(S D 1.22)\end{array}$ & $\begin{array}{l}M=13.50 \\
(S D \quad .74)\end{array}$ & $6.8200 \% *$ \\
\hline $\begin{array}{l}\text { Work } \\
\text { Hours }\end{array}$ & $\begin{array}{c}M=32.00 \\
(S D 9.07)\end{array}$ & $\begin{array}{c}M=32.00 \\
(S D 11.49)\end{array}$ & $\begin{array}{c}M=14.00 \\
(S D \quad 6.72)\end{array}$ & $\begin{array}{l}M=17.70 \\
(S D 9.82)\end{array}$ & $10.3630 * * *$ \\
\hline $\begin{array}{l}\text { Years of } \\
\text { Experience }\end{array}$ & $\begin{array}{c}M=4.93 \\
(S D \\
S .09)\end{array}$ & 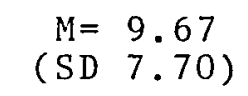 & 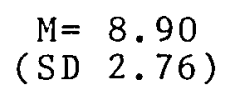 & $\begin{aligned} M= & 6.86 \\
(S D & 3.48)\end{aligned}$ & $5.1100 * * *$ \\
\hline
\end{tabular}

Note: If $* * * \mathrm{p} \leq .000$ 
considered an appropriate test for ANOVA procedures as it can account for unequal group sizes (Munro, Visitainer, Page, 1986; Waltz \& Bausel1, 1981).

Additional Findings

The series of statistical procedures using factorial design two-way analysis of variance and regression procedures were repeated to examine the interaction effects of perceived difficulty in assuming the student role and professional role transition. Subjects had rated the degree of difficulty and the conflict effect contributed by each of the variables (number of occupied roles, focal role occupancy, previous education and work experience). These factors were integrated into the variables, and focal role commitment was retained in the model.

Seventeen percent of the variance of role conflict was explained. Major predictors were multiple roles and focal role commitment. The three percent variance in professional support remained unchanged. Seven percent of the variance in professional role conception discrepancy and three percent of service role conception discrepancy were explained with major effects due to role conflict. Analysis of variance by part-time and full-time student status was performed. A significant difference in ideal professional role conception $(F=3.66, \underline{p} \leq .05)$ was seen with full time students (more than 20 hours at school 
and study per week) having a higher mean score ( $M=28.86$, SD .90 vs $M=26.76, \operatorname{SD} 2.85)$. There were no other significant main or interactive effects.

Respondents were asked to identify the professional person that had provided them with professional support since their return to school. A faculty member was mentioned by 99 (41\%) respondents; a clinical professional nurse was named by 111 (45\%); and 32 (14\%) selected other professionals i.e., doctors, social workers, clergy, or psychologists. A oneway analysis of variance by these three major categories indicated a significant difference in the number of work hours $(M=33.77, S D 9.45)$ for the group that had selected the clinical professional nurse and the reported work hours $(M=27.34, S D 11.81)$ of the group that indicated faculty as support person and work hours ( $M=27.90, S D 13)$ of group selecting the non-nurse professional support person. Although, there were no significant differences among the means of the three groups, the faculty support group reported the lowest amount of perceived support $(M=219.37$, SD 43.12), the clinical nurse support group was next with $M=226.49$ (SD 27.05 ), and non-nurse support group had a $M=228.37$ (SD $28.37)$.

\section{Chapter Summary}

This chapter presented the discussion of the development of a simplified model as a result of data 
reduction and regression analyses that determined the direct and indirect effects of the study variables. Results of the path analysis were used in the discussion of each of the hypothesis statements. Group differences were reviewed. A series of post hoc analyses with all the study variables was reported citing some significant differences. The assumptions underlying residual analysis and analysis of variance were also discussed. 


\section{Chapter V \\ Discussion}

A primary focus of this study was to examine several variables unique to reentry students as potential predictors of professional role transition. Path analysis was used as an analytic tool that resulted in the explanation of four percent of the variance in the service role conception and professional role conception discrepancies.

A simplified model was constructed for the study with service and professional role conception discrepancies as separate outcomes. This was done for clarity in explaining the model. The model includes different predictor variables for the final outcome of professional role transition as measured by the two role conception scales. The direction and degree of effects by the predictor variables are indicated on the model in figure 2 .

Professional support was not significantly predictive of any other variables. Professional support is a relatively new concept that may require further definition. This finding is similar to the results from Goldberger's (1990) study with hypertensive patients and 
adherence to a prescribed regimen in which three percent of the variance in professional support was explained. Innovative changes made by faculty to meet the needs of reentry students may not have been perceived as professional support by the adult students (Rather, 1990). Although a large number of subjects (99 or 41\%) identified a faculty member as a professional support person the mean score for perceived support by this group was lower $(M=219$ than the group selecting a clinical nurse $(M=226)$ or non-nurse professional $(M=228)$ support person. Previous research has indicated that students did not perceive faculty as recognizing the impact of the student role on their responsibilities involved with their other adult roles or providing assistance in meeting those demands (Baj, 1985; Beeman, 1988; Green, 1988; Jackson, 1984). Dalme (1983) noted that influence of faculty diminished as students spent additional time in the clinical setting with other reference groups.

Since conflicting studies exist as to the value of support on the reduction of stress and role transition, the actual conflict may not diminish due to the presence of supportive measures (La Rocco, House, and French, 1980). Gottlieb (1983) stated that professional support is most beneficial in crisis situations rather than in long term situations. Perhaps, the students in this study 
were beyond the initial critical adjustment phase, and had established other means of support. Another explanation might be that the rewards of the anticipated degree outweighed the temporary conflicts experienced in the student role (Rather, 1990).

The strongest positive predictor of role conflict was the number of occupied roles. The findings support the functionalist aspects of role theory (Hardy \& Conway, 1988), and are consistent with previous descriptive studies of reentry student characteristics (Baj, 1985; Campaniel10, 1988; Green, 1988; Jackson, 1984; \& King, 1986). Contemporary as well as earlier studies have indicated that individuals have difficulty balancing the several roles in addition to the student role without some degree of conflict (Lee, 1988; Mac Lean, Knoll \& Kinney, 1985; Merritt, 1983).

The strongest negative predictor for service role conception discrepancy was the current employment role. For professional role conception discrepancy, the strongest positive predictor was role conflict. The positive direction of the role conception discrepancies is consistent with previous studies in which groups of subjects reported that service and professional role conceptions were not practiced to the level of their expectations (Bellinger, 1988; Corwin, 1968; Krammer, 1974; Pieta, 1976). 
The high ideal service role conception $(M=4.6)$ and professional role conception $(M=4.4)$ scores are also consistent with previous results with members of the nursing profession and students (Pieta, 1976; Whelan, 1984). These findings support the socialization theory framework that similar values are held by members of a profession, and individuals who aspire to that profession (Rotter, 1982). The results are interesting since male and military personnel have been included in this study. Another interesting finding is the similarity in the ideal bureaucratic role conceptions of the two small comparison groups. The Navy group mean of 3.60 was slightly higher than the RN group mean of 3.05 . This finding could be of educational and clinical significance. An additional relevant finding is the higher scores for ideal, actual, and discrepancy in professional role conception scales reported by the military and RN male subjects than those reported by the female groups.

The small mean differences $\mathrm{M}_{0}=1.32(\mathrm{SD} 3.54)$ of service role discrepancy and $M_{D}=1.59(\mathrm{SD}-.07)$ of professional role discrepancy may be indicative of greater role congruency between the ideal and actual role conceptions of reentry students. This finding is supported by Lawler \& Rose (1987) who said that the work place may have a greater socializing influence on professional role orientation than previously considered. 
The results of their study suggested that reentry nurse students were more professionally oriented than the generic baccalaureate or associate degree graduates. They also reported that $51-70 \%$ of returning students had planned their education as a two-step process. This finding may be of great importance to the nursing profession.

The negative predictor relationship of the work role on service role conception supports earlier reports of dissatisfaction with current staff positions. The desire of many returning students is to obtain the additional education as a means of career mobility rather than to bring improvements to their current position (Schoen, 1982). The reality of the work environment may also have a greater impact on the student who continues to work, and believes that the values of the educational setting are too idealistic and unattainable.

The absence of strong predictor variables on professional role transition is consistent with previous studies. Although student attitudes are frequently equated with those of their faculty, studies conducted by Schoen (1982) and Frisch (1987) indicated that role orientations of reentry students did not drastically change during the educational process.

This may indicate that faculty have less influence on the returning student, or that students were resistant to 
change. Perhaps, the reentry students brought higher professional ideals into the academic setting and did not see the need to change role orientation (Lynn, Mccain \& Boss, 1989). Frisch (1987) commented that returning students had developed critical thinking and reasoning skills through their experience in the clinical setting. In the post hoc analysis, respondents who selected the clinical nurse as their support person also worked more hours than the other two groups. This finding supports previous research results on the influence of reference groups on students' perceptions (Dalme, 1983; Hardy \& Conway, 1988; Kramer, 1974).

Age and sex, two variables not included in the model, but used as control criteria for establishing the comparison groups, were examined for correlation with the remaining variables. Age was correlated with the number of occupied roles $(r=.17, p \leq .00)$ and the work role $(r=13, p \leq .03)$. There were inverse correlations between sex and roles $(x=-.16, p \leq .00)$, work role $(r:=-.17, \underline{p} \leq .00)$, and role conflict $(r=-.11$, $\underline{p} \leq .03)$ and a positive correlation between sex and professional support $(x=.13, \underline{p}-.16 \leq .02)$. None of these are high correlations, but may be meaningful areas to study in the future. Age and gender grouping differences in the current study were of interest due to the inclusion of male subjects. 
Strengths and Limitations

Limitations of this study are based upon a framework developed by David Krathwohl (1985). A logical chain of reasoning was used to judge the internal validity, or Linking Power, (LP) of the study design. Judgment of the external validity, or Generalizing Power, (GP) is largely dependent upon the strength of the LP.

Internal Validity--Linking Power (LP).

An extensive literature review related to the selected variables in this study formed the foundation of the theory and hypotheses. Personal interviews made by the investigator with reentry students in both groups lend credibility to the proposed theory. Selection of the predictor variables was strongly supported by the information provided by these sources. The direction of effect was also made with confidence because of previous findings.

The instruments developed for construct validity were designed within the principles of homogeneity to determine the presence or differences of that construct (Nunnally, 1978). Conditions of the study were constructed to be congruent with the purposes of the study. The path model is a valuable method for testing a proposed theory, and a correlational design is appropriate for this stage of the study (Munro, Visintainer \& Page, 1986; Polit \& Hungler, 1987; Volicer, 1984; Waltz \& Bausell, 1981). 
Selection of subjects in group I (RN) from local and regional public and private generic baccalaureate programs yielded a representative sample of that group of reentry students. Group II (Military personnel) represented the current population of MECP students enrolled in public and private generic baccalaureate programs in the U. S.

As an additional control of the study conditions, selection of subjects was limited to those who were enrolled in National League of Nursing (NLN) accredited programs. Schools were randomly selected from the NLN 1isting. To overcome problems of lowered response rates for mailed questionnaires, assistance was requested from contact people in institutions with whom students were familiar (Shelley, 1984).

Data collection procedures were given careful consideration to ensure authenticity of information, and to rule out rival hypotheses. Input for computer analysis was closely monitored, and acceptance levels were established prior to analysis of data. The use of inferential statistics and multiple regression procedures are appropriate for path analysis and correlational designs (Polit \& Hungler, 1987; Waltz \& Bausel, 1981).

Empirical studies conducted with other sample groups have been included to reinforce the descriptive and theoretical nursing references. A credible result is dependent upon the selection of a sufficient sample size, 
and the appropriate significance level of sensitivity for changes in co-variation of variables (Krathwohl, 1985). The sample size was appropriate according to the power analysis estimate, and number of predictor variables needed for multiple regression (Cohen, 1977; Tabachnick \& Fidell, 1983) .

External Validity--Generalizing Power (GP). Strong support from the literature regarding the proposed theoretical model suggests that findings can be generalized to the populations from which the samples were drawn. The use of regional NLN accredited generic baccalaureate schools throughout the U. S. lends assurance that samples are representative of the total population of re-entry nursing students.

The instruments were tested for reliability and validity of construct and content measurement. The use of appropriate statistical measures and computer package for analysis also contributed worth to the trarslation generality. However, the permanence for translation generality may be limited due to socio-cultural change and with the passage of time (Krathwohl, 1985).

Generality of findings can be inferred to the general population of reentry nursing students enrolled in the baccalaureate programs described in the study. Although measures have been taken to ensure adequate representation, there is always the question of subjective 
responses. Volunteers may not reflect the opinions of persons who did not choose to participate.

Precautions have been taken to minimize rival

explanations due to selection, mortality, instrumentation, misinterpretation, and researcher expectancy effect that place limitations on generalization of findings (Campbell \& Stanley, 1963). Major problems for this type of study are the use of volunteer subjects and the possible maturational changes that may occur due to the length of the instrument, and mortality of subjects because of lack of interest, limited time, and unfamiliarity with the investigator. Individuals who must fulfill multiple roles may not be able to participate.

A major limitation of the study design is the lack of in-depth investigation of variables that contribute to role conflict, professional support, and role transition. close attention to the selected number of variables in the study, and simplicity of the model were considered to lessen the possibility of loss of subjects.

The assistance of contact persons familiar with the students was used to help encourage participation. The request to complete the questionnaire at the end of a clinical day helped to control the conditions for completing the form. Subjects also had the option of selecting that day within a two-week time frame. A cover letter clearly identified the researcher and included the 
purpose of the study, guaranteed anonymity to the respondents, and mentioned the potential benefits of the research in order to gain participation. Additional Limitations

The generality of the study is limited by the use of a recruited sample, and the diversity in the background, educational, and work characteristics of reentry students, therefore a fairly large sample was needed. Limitations of personal time, and resources of the researcher also influenced conditions of the study. Due to these limitations and institutional restrictions, personal contact with subjects in distant geographical areas was not considered. Although precautions were taken to minimize the response to mailed questionnaires, a $32 \%$ response rate from the $\mathrm{RN}$ group and a $44 \%$ response rate from the Navy group were received. A 50\% response rate is the expected norm (Shelley, 1984).

Finally, the selection of instruments has been made following a comprehensive review of available tools. Although these have been based on theoretical and empirical findings that have established reliability and validity, the professional support scale and role conflict inventory have not been used on large samples. Male subjects have not been previously tested by the role conception tool. Caution for interpretation of results will be necessary. One of the weaknesses of path or 
causal models is that they are rarely comprehensive when dealing with humans as there can be many unexplained residual causes for phenomenon (Polit \& Hungler, 1987). Implications for Nursing Research

The role conflicts experienced by reentry students will continue to be of interest to nurse researchers. This study suggests that further research is needed to identify additional factors that influence role conflict and the role transition process. The similarities noted in the characteristics of the military and RN student groups suggest that research findings could be applied to a wider population of reentry students than previously reported in the nursing literature.

Reentry students may already have a greater professional role conception due to their association with nurse clinical specialists. Much of the unique body of knowledge of a profession is gained through practical experience. The sense of mission, service, ethical considerations, commitment and accountability are acquired through association with role models within the profession. It would be interesting to study the influence of faculty who are involved in clinical practice on the role conceptions of reentry students. Since role transition may not take place during the relatively short time in academia, future investigations may be enhanced by 
monitoring student progress through the educational program and back into the practice world.

The impact of professional support on the transition process is also a prime field for future study. The relatively new concept shows promise as a mediating variable in the reduction of role stress and facilitating role transition. Since previous research has indicated that support does not actually reduce the main effects of role conflict, further investigation is needed regarding its influence on coping with stressful situations.

In this study three categories of the professional support person emerged that included faculty, clinical nurses, and non-nurse professionals. Further research is needed to determine the role of the particular support person in relation to role conflict and role transition. Professional support as perceived by students and faculty may be significantly different. Clarification of these concepts may provide new insights as to the value of professional support.

The work role and multiple role involvement were primary contributors to role conflict in the current study. Post hoc analysis also included the influence due to family focal role commitments especially those of spouse and parent for both male and female respondents. Frequent comments regarding the devaluation of previous education and work experience by the baccalaureate faculty 
were noted in the qualitative data, and supported by previous research. The needs of reentry students cannot be fully understood without understanding their perspective and meanings attached to their social roles. Several interesting questions remain to be investigated. Ethnic and cultural influences may have a significant influence on the model variables. Refinement of the model and inclusion of additional items are needed for future study with different populations of reentry students. other instruments may prove useful in identifying relationships.

Implications for Nursing Practice

This study supports previous research in describing the demographics of reentry students. The increasing number of health care personnel who continue to work while attending classes is of major interest to nurses in the practice setting. Work schedules may be affected as well as the quality of patient/client care. Nursing care may be enhanced because of the exposure to concepts introduced in the advanced educational curriculum. Continuity of care may also be disrupted by the demands of the student role.

The additional education may not have the expected positive effect on direct nursing care as graduates change work positions. On the other hand, the additional learning may indirectly affect nursing care as these 
individuals move into management and supervisory positions.

Perhaps, the greatest influence on nursing practice is the role transition that occurs over time. The recognition of the newly acquired skills by health care administrators and opportunities to implement change may improve job satisfaction of nurse employees. The current costs to health care organizations for recruitment and retention of qualified professional nurses has escalated during the past several years. The continued support for higher educational preparation may actually reduce attrition rates and replacement costs while increasing patient/client satisfaction with care. Implications for Nursing Education

The increasing number of reentry students who seek advanced education present many challenges to nurse educators. Meeting their unique and diverse needs in planning learning activities is especially difficult within the generic or basic nursing program structure. Recognizing that reentry students may take longer to complete the program due to involvement in other social roles may be the first step in implementing flexibility into the program.

Educators are also concerned with providing meaningful activities that will enhance the previously acquired skills. Much of the rhetoric of the higher 
degree program may be perceived by the reentry student as too idealistic for the practice setting. Faculty need to develop an awareness of the powerful influence on role conceptions of students who have continued contact with the work place.

Faculty must also evaluate what concepts should be included in professional support and explore their role in providing assistance. Faculty need to recognize that professional support may not have the expected positive effect on reduction of role conflict or on role transition. Nurse educators need to evaluate the psychological and physiological effects of role conflict on learning, and be knowledgeable about the process of adult learning. Emphasis should be placed on methods to facilitate progression through the educational process. Anticipatory socialization has been suggested as an effective approach to assist with the transition to the student role. Validation of previous learning that is non-threatening, flexibility in course schedules, and counseling have also been mentioned as helpful measures. Eighty-five percent of the subjects in this study reported satisfaction with nursing. The program structure may actually be enhanced throughout the inter-mixing of basic and advanced students through sharing of their knowledge and skills. These activities may also assist in 
the internalization of professional role concepts for both groups of students.

Summary

This study has described and explained the relationships between demographic characteristics of reentry students and their impact on role conflict and professional role transition. Two groups of reentry students were studied and found to have similar characteristics. This is an interesting finding since military and males were included in the sample. The relationships are supported by the literature and by the theoretical framework. Additional information was provided through data analysis regarding the strength and direction of the relationships. The criteria established by Krathwohl (1985) for internal and external validity were used to ensure internal and external validity. Additional research needs to be done to determine if the theoretical model can be supported in other samples of reentry students. Additional variables contributing to role conflict and role transition need to be identified. Concepts to be included in the concept of professional support and the role of the professional support person need further investigation. 
REFERENCES

Reproduced with permission of the copyright owner. Further reproduction prohibited without permission. 
References

Alverez, A. (1984). Selected characteristics of male registered nurses in New Jersey. Nursing Forum, 21, $166-173$.

Asher, H. (1983). Causal modeling. Beverly Hills, CA. Sage Publications.

Baj, P. (1985). Demographic characteristics of $\mathrm{RN}$ and generic students: Implications for curriculum Journal of Nursing Education, 24(6), 230-236.

Bardossi, K. (1980). Why BSN programs drive nurses crazy. $\underline{\mathrm{RN}}, \underline{43}(2), 53-64$.

Barnett, R., \& Baruch, G. (1985). Women's involvement in multiple roles and psychological distress. Journal of Personality and Social Psychology, 49(1), 135-145.

Baruch, G., \& Barnett, R. (1986). Role quality, multiple role involvement, and psychological well-being in midlife women. Journal of Personality and Social Psychology, 51 (3), 578-585.

Beeman, P. (1988). RNs' perceptions of their baccalaureate programs: Meeting their adult learning needs. Journal of Nursing Education, 27(8), 364-370.

Bellinger, S. (1988). The relationship of selected variables to role orientation/socialization among nursing students. Unpublished Doctoral Dissertation. Univ. of No. Illinois. 
Betz, C. (1985). Students in transition: Imitators of Role Models. Journal of Nursing Education, 24 (7), $301-303$

Beutell, N., \& Greenhaus, J. (1983). Integration of home and nonhome roles: Women's conflict and coping behavior. Journal of Applied Psychology, 68(1), 43-48.

Biddle, B. (1979). Role theory: Expectations, identities, and behaviors, S. F.: Academic Press.

Blatchley, M., \& Stephan, E. (1985). RN student in generic programs: What do we do with them? Journal of Nursing Education, 24(7), 306-308.

Brainard, N. (1983). From RN to BSN. American Journal of Nursing, $\underline{83}(3), 490$.

Brief, A., Aldag, R., Van Sell, M., \& Melone, N. (1979). Anticipatory socialization and role stress among registered nurses. Journal of Health and Social Behavior, 20, 161-166.

Bueche, M. (1986). Re-entry women in baccalaureate nursing programs: The achievement of selected developmental tasks. Journal of Nursing Education, $\underline{25}(1), 15-19$.

Burr, W. (1972). Role transitions: A reformulation of theory. Journal of Marriage and the Family, 34, 407-416. 
Burrows, A. (1982). Nursing role conceptions restructuring ability and integrative resolution of nursing care dilemmas. Unpublished Doctoral Dissertation. N.Y. University. Callero, P. (1986). Toward a Meadian conceptualization of role. The Sociological Quarterly, 27(3), 343-358. Callin, (1983). Going back to school: An open letter to a nurse thinking of returning for further education. Journal of Nursing Education. $14(4), 21-27$. Campaniello, J. (1988). When professional nurses return to school: A study of role conflict and well-being in multiple role women. Journal of Professional Nursing. pp. $136-140$.

Campbell, D., \& Stanley, J. (1963). Experimental and quasi-experimental designs for research. MD:

Carnegie Found.

Carroll, T., \& Artman, S. (1988). Fitting RN students into traditional programs: Secrets of success. Nursing and Health Care, $9(2), 89-91$. Cohen, J. (1977). statistical power analysis for the behavioral sciences (Rev. ed.). NY: Academic Press. Conway, M. (1983). Prescription for professionalism. In N. Chaska (Ed.), The nursing profession: A time to speak (pp. 29-37) . NY: McGraw Hill. 
Corwin, R. (1968). The professional employee: A study of conflict in nursing roles. The American Journal of Sociology, pp. 604-615.

Dalme, F. (1983). Nursing students and the development of professional identity. In N. Chaska (Ed.), The nursing profession: A time to speak (pp. 134-145). NY: McGraw Hill.

Edwards, J., \& Lenz, C. (1987). Regional campuses ease returning to school woes. Nursing and Health Care, $\underline{8}(8), 479-480$.

Foreman, M. (1988). Men in nursing: Would be doctors? Professional Nurse Quarterly, $\underline{3}(1), 1-2,18$. Forrester, D. (1983). The relationship between sex-role identity and perceptions of nurse role discrepancy among professional nurses employed in hospital settings. Unpublished Doctoral Dissertation. N. Y. University. Frisch, N. (1987). Cognitive maturity of nursing students. Image: Journal of Nursing Scholarship, 19(1), 25-30. Gilbert, L., \& Holahan, C. (1982). Conflicts between student/professional, parental, and self-development roles: A comparison of high and low effective copers. Human Relations, $\underline{35}(8), 635-648$. Gottlieb, B. H. (1983). Social support strategies. Beverly Hills, CA: Sage Publications. 
Goldberger, D. (1987). Development of an Instrument to Measure Professional Support. Unpublished Manuscript. University of San Diego. San Diego. CA:

Goldberger, D. (1990). Impact of stress and coping on adherence and health status in patients with hypertension. Unpublished Doctoral Dissertation. University of San Diego, San Diego, CA. Goldstein, J. (1980). Comparison of graduating $A D$ and baccalaureate nursing students' characteristics. Nursing Research, $\underline{29}(1), 46-48$.

Goode, W. (1960). A theory of role strain. American Sociological Review, 25, 483-496.

Green, c. (1987). Multiple role women: The real world of the mature RN learner. Journal of Nursing Education, 26 (7), 266-271.

Green, G. (1988). Relationships between role models and role perceptions of new graduate nurses. Nursing Research, 37(4), 245-248.

Grendell, R. (1987, 1988). Personal interviews with ten military corpsmen. San Diego: unpublished. Gross, Y., Takazawa, E., \& Rose, C. (1987). Critical thinking and nursing education. Journal of Nursing Education, 26 (8), 317-323.

Hammer, R. \& Tufts, M. (1955). Nursing's self-image: Nursing education's responsibility. Journal of Nursing Education, 24 (7), 280-283. 
Hardy, M., \& Conway, M. (1988). Role theory perspectives for health professionals (2nd ed.). San Mateo, CA: Appleton \& Lange.

Hillsmith, K. (1978). From RN to BSN: Student perceptions. Nursing outlook, 26(2), 98-102. Hinkle, D., Wiersma, W. \& Jurs, S. (1979). Applied statistics for the behavioral sciences. Palo Alto, CA: Houghton Miflin Co.

Hiraki, A., \& Parolocha, P. (1983). Returning to school: The RN to BSN handbook. Boston: Little, Brown. Holahan, C., \& Gilbert, L. (1979). Conflict between major life roles: Women and men in dual career couples. Human Relations, 32(6), 451-467. Jackson, M. (1984). Entry characteristics of post-RN students: Implications for the future. The canadian Nurse, pp. 20-25.

Johnston, J. (1987). Men in emergency nursing. Journal of Emergency Nursing, $\underline{13}(2), 88-90$.

Kahn, R., Wolfe, D., Quinn, R., Snoek, J., \& Rosenthal, R. (1964). Organizational stress: Studies of role conflict and ambiguity. NY: John Wiley and Sons.

Kessler, J., \& Henderson, K. (1980). Workshops for RN students. In S. Mirin (ed.), Teaching tomorrow's nurse: A Nurse educator reader, (pp. 103-109). Wakefield, MA: Nursing Resources 
Ketefian, S. (1985). Professional and bureaucratic role conceptions and moral behavior among nurses. Nursing $\underline{\text { Research, 34 }}$ (4), 248-253.

King, J. (1986). A comparative study of adult developmental patterns of RN and generic students in a baccalaureate program. Journal of Nursing Education, 25 $(9), 356-371$.

Kopelman, R., Greenhaus, J., \& Connolly, T. (1983). A model of work, family, and interrole conflict: A construct validation study. organizational Behavior Human Performance, $32,198-215$.

Kramer, M. (1974). Reality shock: Why nurses leave nursing. St. Louis: C. V. Mosby.

Krathwohl, D. (1985). Social and behavioral science

Research. S.F.: Jossey-Bass.

Lambert, C., \& Lambert, V. (1988). A review and synthesis on role conflict and its impact on nurses involved in faculty practice. Journal of Nursing Education, 27(2), 54-60.

Lambeth, S., Volden, C., \& Oechsle, L. (1989). Portfolios: They work for RNs Journal of Nursing Education, 28(1), 42-44

LaRocco, J., House, J., \& French, J. (1980). Social support, occupational stress, and health. Journal of Health and Social Behavior, 21 (Sept), 202-218. 
Lawler, T. \& Rose, M. (1987). Professionalization: A comparison among generic baccalaureate, associate degree, and RN/BSN nurses. Nurse Educator, 12(3), 19-22.

Leddy, S., \& Pepper, J. (1989). Conceptual bases of professional nursing. SF: J. B. Lippincott.

Lee, J. (1988). Analysis of coping methods reported by returning RNs. Journal of Nursing Education, 27(7), 309-313.

Levinson, D. (1978). The seasons of a man's life.

NY: Ballantyne Books.

Lewandowski, L., \& Kramer, M. (1980). Role

transformation of special care unit nurses. Nursing

Research, $\underline{29}(3), 170-179$.

Lum, J. (1988). Reference groups and professional socialization in Role theory Hardy \& Conway eds. CN : Appleton-Century Crofts.

Lynn, McCain \& Boss (1989). Socialization of R.N. to B.S.N. Image, Journal of Nursing Scholarship, 21(4), $232-237$.

Mac Lean, T., Knoll, G., \& Kinney, C. (1985). The evolution of a baccalaureate program for RNs. Journal of Nursing Education, 24 (2), 53-57.

Marks, S. (1977). Multiple roles and role strain: Some notes on human energy, time and commitment. smerican Sociological Review, 31, 921-936. 
Maurin, J. (1983). Role: $\AA$ look at role theory and role change. In D. Shane (Ed), Returning to school pp. 123-129. Englewood Cliffs, NJ: Prentice Hall. McBride, A. (1989). Experience with multiple roles. Reflections. $15(3), 8-9$.

Meleis, A., \& Dagenais, F. (1981). Sex-role identity and perception of professional self in graduates of three nursing programs. Nursing Research, 30(3), 162-167. Menger, G. (1988). A comparative study of transitional role strain in reentry women students. Unpublished Dissertation. Texas Tech University. Merritt, S. (1983). Learning style preferences of baccalaureate nursing students. Nursing Research, $\underline{32}(6), 367-372$.

Merton, R. (1961. Social theory and social structure. Il: Free Press Publications.

Minnigerode, F., Kayser-Jones, J., \& Garcia, G. (1978). Masculinity and femininity in nursing. Nursing Research, 27(5), 299-302. Munro, B. \& Sexton, D. (1984). Path analysis: A method for theory testing. Western Journal of Nursing Research, 6(1), 97-105.

Munro, B., Visintainer, M, \& Page, E. (1986). Statistical methods for health care research. St. Louis: J. B. Lippincott. 
Murdaugh, C., \& Hinshaw, A. (1986). Theoretical model testing to identify personality variables affecting preventive behaviors. Nursing Research, 35(1), 19-23. Murdock, J. (1987). Counseling clears the way for return-to-school decisions. Nursing and Health Care, $\underline{8}(1), 33-36$.

Muzio, L., \& Ohasi, J. (1979). The RN student: Unique characteristics, unique needs. Nursing outlook, $\underline{27}(5), 528-532$.

Norbeck, J. (1981). Social support: A model for clinical research and application. Advances in Nursing Science, pp. 43-59.

Nunnally, J. (1978). Psychometric theory. S.F.: Mcgraw Hill.

Nuwayhid, K. (1984). Role function: Theory and development. In Introduction to nursing: An adaptation model (pp. 284-305, 405-427). In C. Roy (Ed.), N.J.: Prentice Hall.

O'Shea, H. (1982). Role orientation and role strain of clinical nurse faculty in baccalaureate programs. Nursing Research, 31(5), 306-310. Pedhazur, E. (1982). Multiple regression in behavioral research. (2nd. Ed.) S. F. : Holt, Rinehart \& Winston. 
Pierce, P. (1981). Hospital and supplemental agency employed nurses: A comparison of role orientation, accountability, and descriptive variables. Unpublished Doctoral Dissertation. University of Texas, Austin. Pieta, B. (1976). A comparison of role conceptions among nursing students and faculty from associate degree, baccalaureate and diploma nursing programs and head nurses. Unpublished doctoral dissertation. State University of $\mathrm{N}$. Y. at Albany.

Polit, D. \& Hungler, B. (1989) . Nursing research: Principles and methods. St. Louis: J. B. Lippincott. Queen, P. (1984). Resocializing the degree-seeking RN: A curriculum thread. Journal of Nursing Education, $\underline{23}(8), 351-353$.

Rapson, M. (Ed.). (1987) - Collaboration for articulation: RN to BSN. N.Y.: National League for Nursing. (Pub.\#412181).

Rather, M. (1990). The lived experience of returning registered nurse students: A Heideggerian hermeneutical analysis. Unpublished Doctoral Dissertation. The University of Wisconsin. Raudonis, B. (1987). Adult education: Its implications for baccaluareate nursing education. Journal of Nursing Education, 26 (4), 164-166. 
Rencion, D. (1988). The registered nurse student: A role congruence perspective. Journal of Nursing Education, $\underline{27}(4), 172-177$.

Rizzo, J., House, R., \& Lirtzman, S. (1970). Role conflict and ambiguity in complex organizations. Administrative Science Quarterly, 15(2), 150-163.

Rothert, M., Talarczyk, G., Currier-Jayne, C., \& Mccartney, M. (1988). Joining forces to meet needs of RN learner. Nursing and Health Care, $9(5), 261-262$.

Rotter, J. (1982). The development and application of social learning theory. N.Y.: Praeger Pub. Sarbin, T., \& Allen, V. (1968). Role theory. In L. Lindzey \& Aronson (eds). The handbook of social psychology (2nd ed. Vol. 1, pp. 488-567) . Reading, MA: Addison Wesley.

Schlotfeldt, R. (1981). Nursing in the future. Nursing outlook, 29(5), 295-301.

Schoen, D. (1982). A study of nurses' attitudes toward the BSN requirement. Nursing and Health Care, $\underline{3}(7), 382-387$. Shane, D. (1980). The returning-to-school syndrome. Nursing, $80(6), 86-88$. Shane, D. (1983). Returning to school: A guide for nurses, Englewood Cliffs, N.J.: Prentice-Hall. Shelley, S. (1984). Research methods in nursing and health, Boston: Little Brown. 
Strauss, A. (1956). The social psychology of George

Herbert Mead. Chicago: Univ. of Chicago Press. (p. 128-294) .

Stryker, S., \& Statham, A. (1985). Symbolic interaction and role theory. In G. Lindzey \& E. Aronson (Eds). Handbook of social psychology (3rd ed., pp. 311-377). NY: Random House.

Tabachnick, B. \& Fidell, L. (1983). Using multivariate statistics. S. F.: Harper \& Row.

U.S. Department of Health and Human Services, Health Resources and Services Administration, Bureau of Health Professions, Division of Nursing (1990). The registered nurse population: Findings from the national survey of R.N.S. Washington, D.C.: U.S. Government Printing office.

Uphold, C. (1983). Using an individualized clinical evaluation: Strategy to motivate the RN student. Journal of Nursing Administration, 22(9), 397-401. Urden, L. (1987). Development of an instrument to measure professionalism. Unpublished manuscript. University of San Diego. San Diego, CA. Verran, J. \& Ferketich, S. (1984). Testing linear model assumptions: Residual analysis. Nursing Research, $\underline{36}(2), 127-129$.

Volicer, B. (1984). Multivariate statistics for nursing research. San Diego, CA: Harcourt, Brace \& Jovanovich. 
Waltz, C. \& Bausell, R. (1981). Nursing Research: Design statistics and computer analysis. Phil: F. A. Davis. Ward, C. (1986). The meaning of role strain. Advances in Nursing science, pp. 39-49. Weinert, C. (1987). A social support measure: PRQ85 Nursing Research, 36(5), 273-277. Weiss, S. (1984). Educating the nursing profession for role transformation. Journal of Nursing Education, $\underline{23}(1), 9-14$.

Whelan, E. (1984). Role-orientation change among RNs in an upper-division level baccalaureate program. Journal of Nursing Education, 23(4), 151-155.

Williams, R. (1983). Teaching employed RNs in BSN programs. Nursing and Health Care, $4(10), 573-575$. Wilson, H., \& Levy, J. (1978). Why RN students drop out. Nursing outlook, 26(7), 437-441.

Woods, N. (1985). Employment, family roles, and mental ill health in young married women. Nursing Research, 34(1), 4-10

Wooley, A. (1978). From RN to BSN: Faculty perceptions. Nursing outlook, 26(2), 103-108. Zanca, J. (1990). Cost containment and technology: Changing the course of oncology nursing. Cancer nursing, $\underline{8}(3), 3$. 
Zorn, J. (1980). A research profile of today's baccalaureate nursing student. The Journal of Continuing Education in Nursing, 11(2), 7-9. 
APPENDIX A

Reproduced with permission of the copyright owner. Further reproduction prohibited without permission. 
1628 Caminito Asterisco La Jolla, CA 92037

February 21, 1990

Name of Director

School of Nursing

Name of College or University

City, state zip code

Dear \#\#\#\#\#:

I am a doctoral student in the Philip Y. Hahn School of Nursing at the University of San Diego. For my dissertation topic I have chosen to investigate the roie conflicts experienced by the adult re-entry students and their perception of the effects of

professional support provided by faculty in their adaptation to the student role and their transition to the professional role. The investigation will include a comparison of the responses from RN students and military corps enlisted personnel who enroll in generic baccalaureate nursing programs throughout the United States. I believe that this investigation is of significance to nursing in light of the current nursing shortage, the declining enrollment of high-school graduates in nursing programs, and the increasing number of adult students who are seeking advanced education as a means for career mobility to meet the challenges of the nursing profession.

In order to ensure that the sample is representative of baccalaureate programs across the country, a National League for Nursing listing was used for a random selection of programs that admit the RN student into the generic program. I would like the opportunity of including your $\mathrm{RN}$ students in the study by having them complete a questionnaire which will take approximately 45 minutes of their time. To accomplish this, I shall appreciate your indicating on the enclosed form the number of RN students currently enrolled in your program together with the name of a faculty person who would be willing to distribute the questionnaires. All responses would be mailed directly to me for group data analysis.

Upon receipt of the information, I will mail the packets to the person you have selected. Following the completion of the study, a summary of the findings will be sent to the participating institutions. I shall appreciate your returning the enclosed form by March 12 in order for me to prepare the appropriate number of questionnaires. If you have further questions, you may contact me at my home (619) 459-9514 or at Point Loma Nazarene College school of Nursing (619) 221-2243.

sincerely yours,

Ruth N. Grendell, DNSc. Candidate, R.N. 
RESPONSE FORM FOR ROLE CONFLICT STUDY/RN STUDENTS

Faculty Contact Person Name

School Name of School

Address City, state Zip code

Number of RN students currently enrolled

PLEASE COMPLETE AND MAIL TO ME IN THE POSTAGE PAID ENVELOPE BY MARCH 12, 1990

Thank you

Ruth N. Grendell

1628 Caminito Asterisco

La Jolla, CA 92037 
APPENDIX B

Reproduced with permission of the copyright owner. Further reproduction prohibited without permission. 
March 31,1990

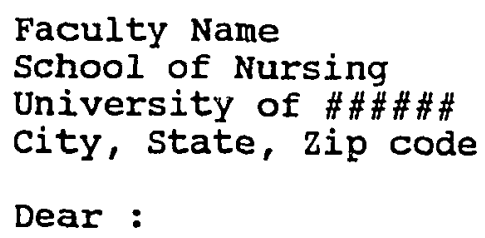

Thank you for consenting to be the contact person for my research study with R.N. re-entry students. Your response to my letter indicated that you have \#\# students enrolled. In order to obtair. a wide distribution of students in the participating schools across the country, I have limited the maximum number of packets for each school at 25 .

For your information, each packet contains a cover letter, a consent form, and a questionnaire consisting of a Role conflict Inventory ( 53 Likert scale items and 5 short answer questions) with a demographic sheet, a Professional Support Scale (65 Likert scale items), and a Professional Role Perception Scale (34 Likert scale items). It should take approximately 30-45 minutes to complete the tool. I have requested that the student complete the questionnaire within two weeks of receiving it and return it to me by April 30. I have also requested that the forms be completed at the end of a clinical day, if possible, so that conditions will be more uniform.

Each packet has been coded for data collection purposes only. I will send a summary of the findings later this year as I complete the dissertation write-up. Again, I am most appreciative of your help in this endeavor.

sincerely,

Ruth N. Grendell, M.S.N., R. N. 1628 Caminito Asterisco

La Jolla, CA 92037

(619) 459-9514 
APPENDIX C

\footnotetext{
Reproduced with permission of the copyright owner. Further reproduction prohibited without permission.
} 
CONSENT FORM

I understand that I am being asked to participate in a research study that will focus on the experiences and needs of re-entry adult students in baccalaureate nursing programs. This study, which is a doctoral dissertation project, will help to evaluate the impact of the student role on the other social roles enacted by adult students. The information will assist in the planning and implementation of programs that will facilitate the educational process.

I have been informed that my responses will be anonymous and confidential, and only group results will be reported. I also understand that my participation will involve completing, one time only, a paper and pencil questionnaire, and that there is no risk involved in my participation. I may contact the

investigator regarding any questions I may have, and I an free to withdraw from the study at any time if I desire.

I understand that the results of this research will be given to me if $I$ ask for them and that the investigator, Ruth N. Grendell (1628 Caminito AsterisCo, La Jolla, CA 92037 phone: (619) 4599514 ) is the person to contact if I have any questions about the study or about my rights as a study participant.

$I$, the undersigned, understand the above explanations and, on that basis, I give consent to my voluntary participation in this research.

Signature of Subject

Date:

Location (e.g., San Diego, CA)

Date:

Date:

Signature of Principal Investigator or Researcher

Signature of Witness

Date:

Please fold and include in envelope with questionnaire. This form will be filed separately from the instrument before any data analysis is done.

Thank you. 
APPENDIX D

Reproduced with permission of the copyright owner. Further reproduction prohibited without permission. 
March 20, 1990

Dear RN Baccalaureate Nursing student:

I am conducting a survey of RN students in generic baccalaureate nursing programs to determine their opinions of their "back-toschool" experiences. I would appreciate your participation in this research project which is part of the doctoral studies at the University of San Diego in California. I believe this study will reveal important information that can be useful in understanding the unique characteristics of the re-entry students, and as a basis for planning curriculum decisions. A summary of the findings will be sent to the schools who have participants in the study.

The questionnaire is divided into three major sections with specific instructions for each subject area. A demographic sheet is also included to gain information on the participants in the study. The number on the instrument is for coding purposes only, and will not be connected with your responses in any way. Your responses will be reported as group data.

In order to provide a representative sample of re-entry, or nontraditional, students in all regions of the country, it is important that you complete the questionnaire and return it to me within two weeks of receiving it or by April 30, 1990. An estimated time for completion is approximately 45 minutes. I would also request that you complete the form at the end of a clinical day so that conditions can be more uniform for all participants. There is no further obligation on your part.

The instrument has been fully approved by the human subjects committee at the University of San Diego, and participation is entirely on a voluntary basis. You may withdraw from the study at any time. If you have any questions, please contact me by letter or phone.

Thank you for participating in this study.

Sincerely,

Ruth N. Grendell, M.S.N., R.N. (Doctoral Candidate)

1628 Caminito Asterisco

La Jolla, CA 92037

(619) 459-9514 
APPENDIX E

Reproduced with permission of the copyright owner. Further reproduction prohibited without permission. 


\section{DEPARTMENT OF THE NAVY \\ NAVAL HEALTH SCIENCES EDUCATION AND TRAINING COMMAND \\ NAVAL MEDICAL COMMAND. NATIONAL CAPITAL REGION \\ 1510 \\ Ser 2HM/DT/1032(086-89) \\ 07 ¿UL 1989}

Ruth N. Grendell, R.N., M.S.N.

Associate Profeggor/Nurging

Point Loma Nazarene College

3900 Lomaland Drive

San Diego, CA 92106

Dear Ms. Grendell:

Thank you for your interest in our Medical Enlisted Commigsioning Program

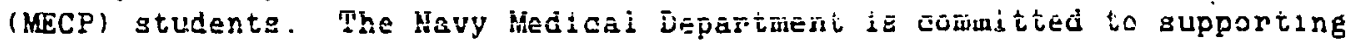

further educational opportunities for its enlisted community and apuld

welcome additionel information that would help our endeavor.

In support of your study, we request that the questionnaires be

distributed from our command and upon completion your inding forwarded

for our review.

My points of contact regarding the Medical Enligted Commissioning Program are DTC Buechler, USN, and HMl Kavanaugh, USN, at telephone

(301) $295-9925 / 0170$.

Sincerely,

R. D. MCCULLAH

Captain

Medical Service Corpo

U.S. Navy

Commanding oflicer

Acting

Reproduced with permission of the copyright owner. Further reproduction prohibited without permission. 
APPENDIX F

Reproduced with permission of the copyright owner. Further reproduction prohibited without permission. 
March 20, 1990

Dear MECP Baccalaureate Nursing student:

I am conducting a survey of MECP students in baccalaureate nursing programs to determine their opinions of their "back-toschool" experiences. I would appreciate your participation in this research project which is part of the doctoral studies at the University of San Diego in California. I believe this study will reveal important information that can be useful in understanding the unique characteristics of the re-entry students, and as a basis for planning curriculum decisions. A summary of the findings will be sent to the Naval Health Science Education and Training Command.

The questionnaire is divided into three major sections with specific instructions for each subject area. A demographic sheet is also included to gain information on the participants in the study. The number on the instrument is for coding purposes only, and will not be connected with your responses in any way. Your responses will be reported as group data.

In order to provide a representative sample of re-entry, or nontraditional, students in all regions of the country, it is important that you complete the questionnaire and return it to me within two weeks of receiving it or by May 7,1990 . If there is a delay in receiving this questionnaire that would prohibit you from meeting this deadline, please complete the form and return it as soon as possible. An estimated time for completion is approximately 45 minutes. I would also request that you complete the form at the end of a clinical day so that conditions can be more uniform for all participants. There is no further obligation on your part.

The instrument has been fully approved by the human subjects committee at the University of San Diego, and participation is entirely on a voluntary basis. You may withdraw from the study at any time. If you have any questions, please contact me by letter or phone.

Thank you for participating in this study.

Sincerely,

Ruth N. Grendell, M.S.N., R.N. (Doctoral Candidate)

1628 Caminito Asterisco

La Jolla, CA 92037

(619) 459-9514 
APPENDIX G

Reproduced with permission of the copyright owner. Further reproduction prohibited without permission. 
I would appreciate having some information about the participants in this study. Please complete the following statements.

Sex : Female Male

Age at last birthday

Years in present relationship with Significant other

Number of children at home: Preschool age Elementary school age Jr. High/High School age other None

Number of hours per week employed

Number of hours per week attending school

Number of hours per week devoted to study time

Date of re-entry to college __ (month) _- (year)

Proposed graduation date.

Years of nursing work since last attended formal schooling. Highest level of education completed: High School Diploma Nursing Program Assoc. Degree Baccalaureate Master Degree (in another field)

Please indicate the number of roles that you currently fulfill that may be affected by your school role. (worker, spouse, parent, daughter/son, citizen, friend, etc.)

of these roles, which one has the primary importance for you?

On a scale from 1-5, with 5 indicating the most conflict, please state the degree of difficulty you have experienced in adjusting to the student role in the baccalaureate program.

Please indicate the factors that have contributed to this difficulty

(mark all that apply)

multiple roles

Specific role

previous education work experience 
APPENDIX $\mathrm{H}$

Reproduced with permission of the copyright owner. Further reproduction prohibited without permission. 


\section{INTRA-ROLE CONFLICT SCALE}

(Grendel I IRCS 1986)

\section{INSTRUCTIONS}

There are 53 items on the questionnaire that are related to the various roles that most people fulfill each day. I am interested in knowing how you feel about the impact of the student role on your other activities. There are no right or wrong answers.

Each of the items has been prefaced with this statement--"since I have returned to school"... Keep this in mind as you read each of the 53 items. For each of the items about the effect of the student role on your life, please indicate the extent to which you agree or disagree by placing an (X) or a ( ) in the most appropriate column on the right side of the page. Your response to each statement should reflect how you feel at the present time.

There are four choices within the rating scale. These are: (1) STRONGLY DISAGREE, (2) INCLINED TO DISAGREE, (3) INCLINED TO AGREE, AND (4) STRONGL $\Psi$ AGREE.

NOTE: Throughout the questionnaire the role of spouse or "significant other" will be represented by the initials--s.0.

EXAMPLE

SINCE I HAVE RETURNED TO SCHOOL:

1. I have neglected my family.

2. All my spare time is used for study.

3. I am exhausted.

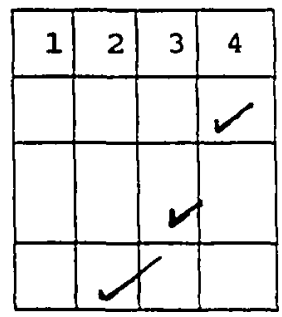

There are five (5) statements following this portion of the questionnaire that ask you to respond with brief comments. The last page requests demographic information.

Mark only one answer per statement and erase completely any answer you decide to change. Be sure to complete the front and back of each page. 


$\begin{array}{ccccc}\text { Strongly } & \text { Inclined } & \text { Inclined } \\ \text { to } & \text { to } & \begin{array}{c}\text { Strongly } \\ \text { Agree }\end{array} & 166 \\ \text { Disagree } & \begin{array}{c}\text { Agree } \\ 1\end{array} & 2 & 3 & 4\end{array}$

SINCE I HAVE RETURNED TO SCHOOL:

1. My spouse (significant other/S.0.) accepts my choice to pursue an education, but resents the time I need for study.

2. I frequently must forego social activities in order to complete homework assignments.

3. At work my assigned tasks seem too easy or boring.

4. My spouse (S.O.) does not understand how much my education lueans to me and discourages me from continuing.

5. I am not motivated to do more than is necessary at work.

6. I am frustrated because my studies have drastically limited by social time.

7. It is difficult for me to establish my priorities because too many demands are made upon me.

8. I am expected to know about new equipment and procedures at work even though my school schedule conflicts with the instructional meetings.

9. I am anxious about my ability to do well in school.

10. I feel "out of touch" with current events and do not feel competent to discuss them when I am with a group of people.

11. I sense that other people expect me to do well in my studies without compromising my other responsibilities.

12. I feel that I am not working to my full capacity at any of my tasks.

13. My S.O. and I argue because my school expenses strain our family budget.

14. I regret that I have lost contact with close friends.

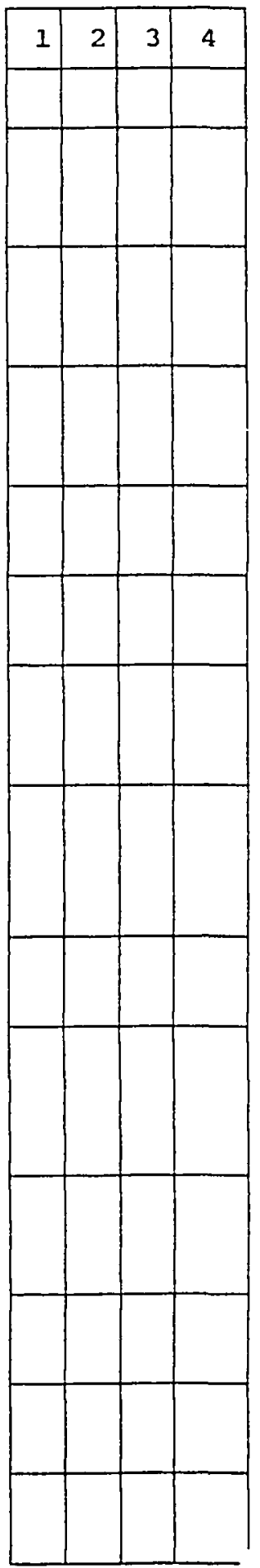

Reproduced with permission of the copyright owner. Further reproduction prohibited without permission. 


$\begin{array}{ccccc}\text { Strongly } & \text { Inclined } & \text { Inclined } & \text { Strongly } & 167 \\ \text { Disagree } & \text { to } & \text { to } & \text { Agree } & \\ & \text { Disagree } & \text { Agree } & \\ 1 & 2 & 3 & 4\end{array}$

SINCE I HAVE RETURNED TO SCHOOL:

15. I feel guilty for asking my family to respect my need for private time to study.

16. I cannot expect my spouse (S.O.) to care for the children when they are ill so that I will not have to miss school.

17. Hy concentration on school work prevents me from fully enjoying social events that I do attend.

18. I must frequently decide between meeting school assignment deadlines and granting requests for attention by my children.

19. My friends do not take my commitment to school very seriously or respect my need to be alone to study.

20. My salary is necessary for our family needs and I must work more hours than I would like.

21. I feel that my children expect more from me just when I need that time to devote to my studies.

22. I have difficulty balancing the opposing requirements of the work role and student role.

23. I cannot predict how my S.0. will react when I am required to spend additional time at school work.

24. I feel self-conscious in the classroom with younger students and do not feel that I am part of the group.

25. I feel that I have failea when I cannot do what others expect of me.

26. I do not feel that I have full family support as I pursue my education.

27. I feel guilty when I take time to relax

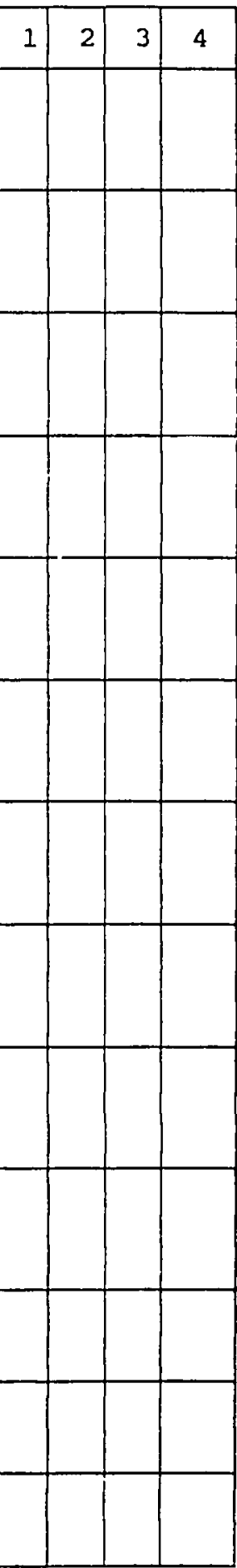
by myself. 


$\begin{array}{ccccc}\text { Strongly } & \text { Inclined } & \text { Inclined } \\ \text { to } & \text { to } & \text { Strongly } & 168 \\ \text { Agree } & \text { Agree } & & 16 \\ 1 & \text { Disagree } & 2 & 3 & 4\end{array}$

SINCE I HAVE RETURNED TO SCHOOL:

28. I am still expected to support my spouse (S.O.) by attending work-related social activities even though my time is limited.

29. My family does not understand my frustrations regarding my school work.

30. I wish my spouse (S.O.) would talk about thoughts and feelings.

31. I feel my past accomplishments have bcen discounted by my instructors.

32. I regret that my social obligations must take a lower priority so that I can attend to my studies.

33. I feel that my family would expect me to interrupt my educational pursuit in order to meet their needs.

34. I have little in common with my colleagues at work.

35. I have had little help and support from family members.

36. I believe my S.0. does not understand when my school schedule conflicts with a planned social time together.

37. I am discouraged when I cannot live up to my own expectations.

38. At work, I am unable to implement some of the knowledge that I have recently learned.

39. I sense that my S.O. feels threatened by my academic achievements.

40. Preoccupation with school has caused me to make more mistakes at work.

41. My family has not taken on household tasks as they promised to do.

42. I am always tired and have no energy to do things that I would like to do.

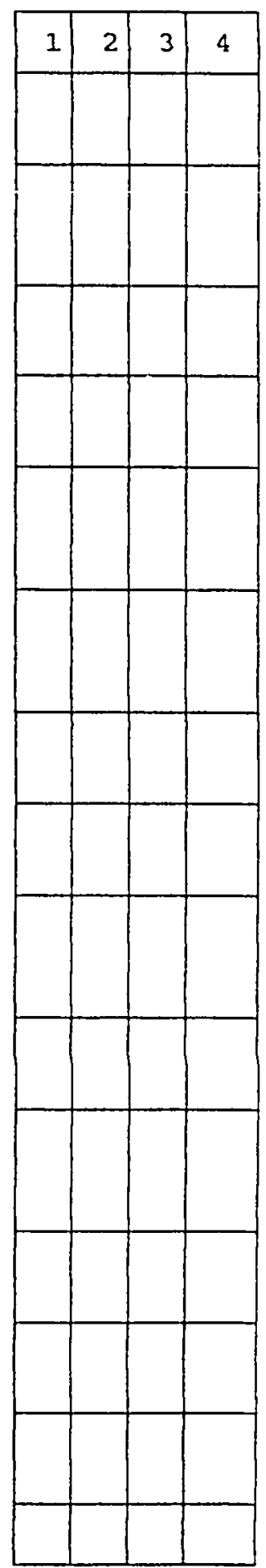




$\begin{array}{ccccc}\text { Strongly } & \text { Inclined } \\ \text { Disagree } & \begin{array}{c}\text { Inclined } \\ \text { to } \\ \text { Disagree }\end{array} & \begin{array}{c}\text { Strongly } \\ \text { Agree }\end{array} & 169 \\ 1 & 2 & 3 & 4\end{array}$

SINCE I HAVE RETURNED TO SCHOOL:

43. My spouse (S.O.) and I have open communication channels and try to solve our problems together.

44. My family continues to depend on me to do most of the household tasks.

45. At work, I am asked to perform work that conflicts with my values.

46. It has been necessary to drop committee and volunteer work that I would like to do.

47. The relationship between me and my $S .0$. is more like that of two separate persons rather than that of a couple.

48. I can readily share new knowledge with my colleagues at work.

49. I realize that some of my close friends do not approve of my return to school.

50. I know I should attend church more often, but that is the only time of the week that I can be by myself.

51. I have not taken good physical care of myself and I do not feel as well as I should.

52. I enjoy attending classes and working outside the home more than doing my household tasks.

53. At times I have thoughts of failing to meet the expectations of my current nursing instructor.

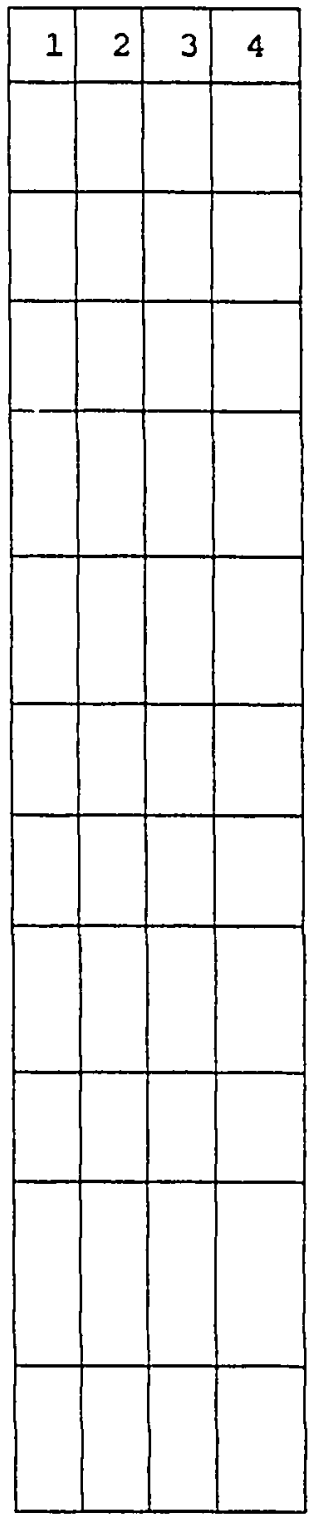

PLEASE GO TO NEXT PAGE 
This portion allows you to expand your answers by asking for a brief commentary to the following statements.

1. What was your motivation for returning to school? (i.e. own personal development, greater career mobility.)

2. State what your response would be if your supervisor made an unreasonable work-time request of you when it would infringe on your study time.

3. How would you handle the situation when your spouse or S.o. asked you to spend the weekend with the family on a favorite family outing or activity when you have an important school commitment?

4. How would you negotiate with your children regarding what you consider to be unreasonable demands on your time?

5. Please provide comments on ways that the return to the academic setting has affected you, but have not been addressed in the questionnaire.

PLEASE GO TO NEXT PAGE 
171

APPENDIX I

Reproduced with permission of the copyright owner. Further reproduction prohibited without permission. 


\title{
PLEASE NOTE
}

\begin{abstract}
Copyrighted materials in this document have not been filmed at the request of the author. They are available for consultation, however, in the author's university library.
\end{abstract}

Professional Support Scale

Pp. 172-174

University Microfilms International 
17.5

APPENDIX J

Reproduced with permission of the copyright owner. Further reproduction prohibited without permission. 
PLEASE NOTE

\begin{abstract}
Copyrighted materials in this document have not been filmed at the request of the author. They are available for consultation, however, in the author's university library.
\end{abstract}

Nursing Role Conceptions

pp. 176-183

University Microfilms International 